\title{
Prevention of Late-life Cognitive Disorders: Diet-Related Factors, Dietary Patterns, and Frailty Models
}

\author{
Francesco Panza • Vincenzo Solfrizzi • Rosanna Tortelli • \\ Francesco Resta $\cdot$ Carlo Sabbà • Giancarlo Logroscino
}

Published online: 3 April 2014

(C) Springer Science+Business Media New York 2014

\begin{abstract}
The need for preventing or postponing the onset of Alzheimer's disease (AD) and delaying or slowing its progression is a direct consequence of the current symptomatic approach of existing drugs for the treatment of AD. Dietary factors may affect the risk of $\mathrm{AD}$ and dementia, with a substantial body of evidence suggesting that certain diets have been associated with a lower incidence of $\mathrm{AD}$ and late-life cognitive disorders. Among healthy diets, higher adherence to a Mediterranean-type diet and to the Dietary Approaches to Stop Hypertension diet was associated with decreased cognitive decline, although the Mediterranean diet (MeDi) combines several foods, micro-, and macronutrients already separately proposed as potential protective factors against dementia. Higher adherence to the MeDi was associated with a reduced risk of cognitive impairment, $\mathrm{MCI}$, and $\mathrm{AD}$, as well as the transition from $\mathrm{MCI}$ to $\mathrm{AD}$, and decreased all-causes mortality in AD patients. Influencing some age-related conditions, such as frailty, may have an impact on the prevention of late-life cognitive decline. Frailty reflects a nonspecific state of vulnerability and a multisystem physiological change and it is a widely recognized risk factor for adverse health outcomes in older persons. At present, no operational definition has been
\end{abstract}

Francesco Panza and Vincenzo Solfrizzi contributed equally to the work.

\section{F. Panza $(\bowtie) \cdot$ R. Tortelli $\cdot$ G. Logroscino}

Neurodegenerative Disease Unit, Department of Basic Medicine,

Neuroscience, and Sense Organs, University of Bari Aldo Moro,

Bari, Italy

e-mail: geriat.dot@geriatria.uniba.it

F. Panza $\cdot$ R. Tortelli $\cdot$ G. Logroscino

Department of Clinical Research in Neurology, University of Bari

Aldo Moro, "Pia Fondazione Cardinale G. Panico," Tricase, Lecce,

Italy

V. Solfrizzi $\cdot$ F. Resta $\cdot$ C. Sabbà

Geriatric Medicine-Memory Unit and Rare Disease Centre,

University of Bari Aldo Moro, Bari, Italy established, although nutritional status, cognition, and mood have been proposed as markers of frailty. Physical frailty may be associated with late-life cognitive impairment/decline, incidence of $\mathrm{AD}$, vascular dementia, non-AD dementias, and $\mathrm{AD}$ pathology in older persons with and without dementia, also suggesting the definition of cognitive frailty as a new clinical condition. The reviewed evidence supports the hypothesis that frailty could be important in the prevention of late-life cognitive disorders, and nutritional influences may be of major relevance. Nutritional interventions might be able to address the impaired nutrition and weight loss of frailty. There is a critical need for randomized, controlled trials investigating the role of nutrition on late-life cognitive disorders and frailty that might open new routes for the prevention and management of cognitive decline and $\mathrm{AD}$, supplementing existing symptomatic approaches, also through the nutritional prevention of frailty.

Keywords Diet - Alzheimer's disease $\cdot$ Dementia $\cdot$ MCI . Dietary patterns $\cdot$ Frailty $\cdot$ Nutrition $\cdot$ Cognitive frailty

\section{Introduction}

The greatest known risk factor for Alzheimer's disease (AD) is advancing age and, due to aging populations, dementia and late-life cognitive disorders are reaching epidemic proportions [1]. The causes of AD and dementia syndromes are, at present, unclear, but some studies have suggested that they may be prevented [2-7]. In a general rethinking of the field, the 2011 criteria developed by National Institute on Aging and the Alzheimer's Association proposed three stages of $\mathrm{AD}$, i.e., preclinical $\mathrm{AD}$, mild cognitive impairment $(\mathrm{MCI})$ due to $\mathrm{AD}$, and dementia due to $\mathrm{AD}$ [8-10], different from the stages currently used to describe $\mathrm{AD}$, also suggesting that the disease begins before the development of symptoms and that new 
diagnostic procedures may have the potential to identify brain changes that precede the development of symptoms [10]. In fact, recent studies on familial [11] and sporadic AD [12•] showed a prolonged preclinical phase of more than two decades before the onset of dementia in which $\beta$-amyloid (A $\beta$ ) deposition is slow and protracted, so confirming the new proposed diagnostic procedures [8-10], and suggesting prevention trials in asymptomatic genetic forms of $\mathrm{AD}$ and in cognitively normal individuals suspected to be at an asymptomatic stage of sporadic AD. However, these amyloid-based prevention trials started only at the end of 2013 [13], and lowering the burden of $A \beta$ with a strategy against the production and the accumulation of this peptide have represented a large portion of the many therapeutic approaches currently under development for the treatment of AD $[14,15]$. However, drugs currently used for the treatment of $\mathrm{AD}$ produce limited clinical benefits, partially stabilizing patients' symptoms, without disease-modifying potential. Therefore, at present, the management of potential risk factors is believed to be the most effective means of preventing dementia, $\mathrm{AD}$, and MCI.

Growing epidemiological evidence supported the hypothesis that modifiable vascular, metabolic, and lifestyle-related factors were associated with the development of cognitive disorders in late life, opening new routes for the prevention and management of these syndromes [2, 5-7]. Currently, one of the most intriguing and appealing links hypothesized in recent years is the association between lifestyle factors, such as diet and dietary habits, and the occurrence of AD [16-18]. If advancing age is the driving risk factor for $\mathrm{AD}$, some agerelated conditions may be strictly linked to dementia and latelife cognitive disorders. Among these conditions, frailty is a multidimensional geriatric syndrome reflecting a nonspecific state of vulnerability and a multisystem physiological change [19]. Frailty also has been associated with an increased risk of adverse health-related outcomes in older persons, including falls, disability, hospitalizations, and mortality $[19,20]$. Genetic, epigenetic, and environmental factors, such as nutrition and physical activity, are strongly related to frailty [21, $22 \cdot]$. However, not only physical but also psychological, cognitive, and social factors contribute to this multidimensional syndrome and need to be taken into account in its definition and treatment. Cognition already has been considered as a component of frailty [23], and it has been demonstrated that it is associated with adverse health outcomes [24, 25]. Therefore, the prevention of frailty is important in preventing cognitiverelated adverse health outcomes, including delirium [26] and late-life cognitive disorders [27]. In this narrative review article, we examined the possible role of macronutrients, food nutrients, dietary patterns, and different frailty models in modulating the risk of $\mathrm{AD}$, dementia, and late-life cognitive disorders, with a focus on the role of nutrition on frailty, in an attempt to explain some underlying mechanisms of the proposed associations between diet-related factors and cognition in older age.

\section{Diet-Related Factors, Dietary Patterns, and Late-Life Cognitive Disorders}

\author{
Micro-, Macronutrients, Foods, and Food Groups \\ and Cognition
}

Deficiencies of some micronutrients (especially, vitamins B1, B2, B6, B12, C, and folate) have been described quite frequently in older people and found to be significantly associated with cognitive impairment [17]. In fact, for example, there is a large body of evidence that maintaining healthy vitamin $C$ levels can have a protective function against $A D$, but avoiding vitamin $\mathrm{C}$ deficiency is likely to be more beneficial than taking supplements [28]. In observational studies and in preclinical models of $\mathrm{AD}$, dietary supplementation of antioxidants [29], B vitamins [30], and polyphenols [31] appeared to be beneficial for $\mathrm{AD}[32,33]$, although many of the results from randomized, controlled trials are contradictory to that of epidemiological and animal studies [34, 35]. Furthermore, a recent population-based study, the Québec Longitudinal Study on Nutrition and Successful Aging, found that low levels of phylloquinone (vitamin K) were related to poor verbal episodic memory performance in older individuals free of cognitive impairment [36].

However, while the impact of micronutrients in cognitive decline has been extensively investigated, few data were available on the role of macronutrient intakes and single foods or food groups in the pathogenesis of age-related cognitive decline and dementia syndromes $[5,17,18,33,37,38]$. Elevated saturated fatty acids could have negative effects on age-related cognitive decline and MCI [39]. Furthermore, at present, epidemiological evidence suggested a possible association among fish consumption, monounsaturated fatty acids (MUFA) [40, 41], and polyunsaturated fatty acids (PUFA) (particularly, n-3 PUFA) and reduced risk of cognitive decline, $\mathrm{AD}$, and dementia [39, 42, 43]. Data from randomized, controlled trials (RCTs) showed that supplementation with docosahexaenoic acid (DHA) and eicosapentaenoic acid (EPA) compared with placebo did not slow the rate of cognitive decline and functional decline [44-46]. However, in the PREDIMED-NAVARRA, a RCT with a follow-up of 6.5 years in older persons, the group supplemented with an extra-virgin olive oil supplement, very rich in MUFA content, had better cognitive performance, and was less likely to become demented $[47 \cdot \bullet]$. The contradictory results between observational studies and RCTs might be due to the duration of RCTs, often not long enough. Therefore, based on the current evidences from human and animal studies, it is not possible to make definitive dietary recommendations in relation to the $\mathrm{AD}$ risk 
on fish consumption and the lower intake of saturated fat from meat and dairy products $[39,48]$ as well as on unsaturated consumption or lower intake of saturated fat in relation to the risk for dementia and cognitive decline. However, a high consumption of fats from fish, vegetable oils, vegetables, and nuts should be encouraged because this dietary advice is in accordance with recommendations for lowering the risk of cardiovascular disease, obesity, diabetes, and hypertension $[39,48]$.

Among macronutrient intakes, single foods, and food groups, poorer cognitive function [49•], and an increased risk for vascular dementia (VaD) [50] were found to be associated with a lower consumption of milk or dairy products. However, the consumption of whole-fat dairy products may be associated with cognitive decline in the elderly [5]. The limited available literature supported the concept that high dairy consumption may be associated with a lower likelihood of cognitive impairment; however, high intakes of full-fat dairy and/ or dairy fats may be associated with declines in cognitive performance [49•, 51]. Dairy may reduce the risk for cognitive impairment by modifying vascular factors linked to detrimental brain changes, particularly via weight reduction [5]. Multiple mechanisms associated with diabetes-related glucose and insulin dysregulation can lead to vascular and neuronal damage [6]. During the past two decades, multiple studies have examined the possible association of diabetes mellitus and different forms of dementia and cognitive impairment [52]. Therefore, a diet high in carbohydrates may be detrimental to $\mathrm{AD}[53,54]$. However, glycemic load reflexing carbohydrate content in food was not associated with a higher risk of $\mathrm{AD}$ [55], not supporting low carbohydrate diets for the prevention of $\mathrm{AD}$ in older age. No reliable data from RCTs on a diet high in carbohydrate and AD were available [32]. The limited epidemiological evidence available on fruit and vegetable consumption and cognition generally supported a protective role of these macronutrients against cognitive decline, dementia, and $\mathrm{AD}$ [5]. However, a very recent meta-analysis on six studies analyzed fruit and vegetables separately and five of them found that higher consumption of vegetables, but not fruit, was associated with a decreased risk of dementia or cognitive decline in older age [56].

Among diet-associated factors, some case-control and cross-sectional and longitudinal population-based studies evaluated the long-term effects on brain function and provided some evidence that coffee, tea, and caffeine consumption or higher plasma caffeine levels may be protective against cognitive impairment and dementia [57, 58, 59•]. In particular, several cross-sectional and longitudinal population-based studies suggested a protective effect of coffee, tea, and caffeine use against cognitive impairment/decline, although the association was not found in all cognitive domains investigated and there was a lack of a distinct dose-response association, with a stronger effect among women than men [59•].
Furthermore, for dementia and AD prevention, some studies with baseline examination in midlife pointed to a lack of association, although other case-control and longitudinal population-based studies with briefer follow-up periods supported favourable effects of coffee, tea, and caffeine consumption against $\mathrm{AD}[57,58]$. Finally, light-to-moderate alcohol use may be associated with a reduced risk of incident dementia and $\mathrm{AD}$, whereas for $\mathrm{VaD}$, cognitive decline, and predementia syndromes the current evidence is only suggestive of a protective effect [60]. Indeed, the body of epidemiological evidence of all research published within the past 10 years suggested that light-to-moderate alcohol use may be associated with a reduced risk of unspecified incident dementia and $\mathrm{AD}$, whereas for $\mathrm{VaD}$, cognitive decline, and predementia syndromes, the current evidence is only suggestive of a protective effect [61-63]. Protective effects of moderate alcohol consumption against cognitive decline are suggested to be more likely in the absence of the AD-associated apolipoprotein E (APOE) $\varepsilon 4$ allele and where wine is the beverage [60]. At present, there is no indication that light-tomoderate alcohol drinking would be harmful to cognition and dementia, and attempts to define what might be deemed beneficial levels of alcohol intake in terms of cognitive performance would be highly problematic and contentious [60].

\section{Dietary Patterns and Late-Life Cognitive Decline}

Dietary factors may affect the risk of cardiovascular disease, also influencing the risk of $\mathrm{AD}$ and dementia [40, 64], with a substantial body of evidence suggesting that certain diets have been associated with a lower incidence of $\mathrm{AD}$ and late-life cognitive disorders [65-67, 68•, 69, 70, 71•, 72• 73]. Singlenutrient analyses ignored the complexity of the diet, and defining dietary exposures as a dietary pattern, a combination of food components that summarizes an overall diet for a study population, may better predict disease risk [74].

Compared with traditional single-food or nutrient methods, the whole-diet or dietary pattern approach is appealing for several reasons. Indeed, the analyses of single nutrients ignore important interactions (additive, synergistic, or antagonist effects) between components of diet and more importantly people did not eat isolated nutrients [5]. Among different dietary patterns, in a recent Japanese population-based study, higher adherence to a dietary pattern characterized by a high intake of soybeans and soybean products, vegetables, algae, and milk and dairy products and a low intake of rice was associated with reduced risk of dementia [71•]. These findings suggested that a traditional Japanese diet characterized by increased intake of fish and plant foods (soybean products, seaweeds, vegetables, and fruits) and decreased intake of refined carbohydrates and animal fats (meat) may be protective against dementia. On the contrary, a high-fat Western diet characterized by higher intake of red and processed meats, 
refined grains, sweets, and desserts may contribute to the development of $\mathrm{AD}$ with increased $\mathrm{A} \beta$ deposition and oxidative stress $[75,76]$. Although epidemiological findings from studies exploring Western diet and the risk of AD were not available [32], a dietary pattern similar to that of Western diet and characterized by a high intake of meat, butter, high-fat dairy products, eggs, and refined sugar has been found in $\mathrm{AD}$ patients in a small study [77]. Another study also have examined a posteriori-extracted dietary patterns in relation to $\mathrm{AD}$, with a dietary pattern strongly associated with lower AD risk and characterized by higher intakes of salad dressing, nuts, fish, tomatoes, poultry, cruciferous vegetables, fruits, and dark and green leafy vegetables and a lower intake of high-fat dairy products, red meat, organ meat, and butter [78]. Two other studies have focused on the cross-sectional link between cognitive function and "healthy" dietary patterns extracted by cluster analysis $[65,79]$. In fact, a healthy diet, characterized by higher consumption of fish by men and fruits and vegetables by women, was also reported to be associated with better cognitive performance [65]. In another populationbased study, higher intake of "whole food" diet (rich in fruit, vegetables, dried legume, and fish) was associated with lower and high consumption of "processed food" (rich in processed meat, chocolates, sweet desserts, fried food, refined cereals, and high-fat dairy products) with higher odds of cognitive deficit [79]. Furthermore, two population-based studies used middle-age dietary exposure assessment, which is critical when focusing on diseases requiring several decades to develop [67, 69]. In a first study on 525 subjects, persons with a high adherence to healthy diet in mid-life, with healthy diet index $>8$ points (an index constructed to assess healthy and unhealthy diet components), had a decreased risk of $\mathrm{AD}$ after a 14-year follow-up [67]. Finally, in the Supplementation en Vitamines et Minéraux Antioxydant, 1994-2002 (SU.VI.MAX) study, in a cohort of 3,054 participants, adherence to a healthy dietary pattern in mid-life (consumption of fruit, whole grains, fresh dairy products, vegetables, breakfast cereal, tea, vegetable fat, nuts, and fish) was positively associated with better cognitive functioning, independently of other health behavior factors [69].

Therefore, maintaining a healthy diet may have an impact on many possible risk factors for cognitive decline, and the models to follow seem to be the Mediterranean diet (MeDi) and the Dietary Approaches to Stop Hypertension (DASH) $\operatorname{diet}[68 \bullet, 70,72 \bullet, 73]$. In particular, the DASH diet, a recommended dietary plan for all Americans, especially those with hypertension [80, 81], contains a high intake of plant foods, fruits, vegetables, fish, poultry, whole grains, low-fat dairy products, and nuts, while minimizing intake of red meat, sodium, sweets, and sugar-sweetened beverages. In a RCT on 124 participants with elevated blood pressure, subjects on the DASH diet or with DASH dietary modification plus weight loss exhibited greater cognitive improvements compared with control subjects [82・•]. In the populationbased Cache County Memory Study (CCMS), the DASH score was one of six behaviors assessed in relation to incident dementia or $\mathrm{AD}$, with dietary behaviors in conjunction with others associated to a decreased risk of incident dementia in a 6-year follow-up [83]. In another analysis from the CCMS, a significant reduction in rates of global cognitive decline was observed with higher levels of accordance with both the DASH and Mediterranean-style dietary patterns in older men and women during an 11-year period [84••]. The Mediterranean-style diet is characterized by abundant plant foods consumption in the form of fruits, vegetables, breads, other forms of cereals, potatoes, beans, nuts and seeds; fresh fruit as the typical dessert; olive oil as the main source of MUFA; dairy products as principally cheese and yogurt; a low-to-moderate consumption of fish; a low-to moderate consumption of poultry; fewer than four eggs consumed per week; low amount of red meat and wine consumed in lowto-moderate amounts, normally during meals [50]. Adherence to a Mediterranean-type diet could be associated with slower cognitive decline, reduced risk of progression from MCI to $\mathrm{AD}$, reduced risk of $\mathrm{AD}$, and decreased mortality in $\mathrm{AD}$ patients, with some notable exceptions $[5,72 \cdot, 85]$. Some very recent systematic reviews and meta-analyses found that a higher adherence to the MeDi was associated with a reduced risk of cognitive impairment, $\mathrm{MCI}$, and $\mathrm{AD}$, as well as the transition from MCI to $\mathrm{AD}[68 \cdot, 86,87]$. Two RCTs are available on this topic $[88,89 \cdot \bullet$; one found inconsistent results although with an inordinately short follow-up of only 10 days [88], whereas the PREDIMED-NAVARRA suggested that nutritional intervention with MeDi supplemented with either extra-virgin olive oil or mixed nuts was associated with improved global cognition in a 6.5-year follow-up, independently of potential confounders [89*0]. This evidence is confirmed by a specific nutrient/food model based of the MeDi in which elevated dietary MUFA, n-3 PUFA, and high fish consumption, alongside high levels of antioxidants from fruit and vegetables, and moderate alcohol consumption may have a beneficial effect on the risk of dementia [73].

\section{Cognitive Frailty: Epidemiological Evidence of a New Clinical Condition}

Operational Definitions of Frailty and Proposed Models

Among potentially modifiable risk factors, the impact of several operational definitions of frailty $[19,24,25]$ (Table 1) on late-life cognitive decline and dementia has been the subject of recent interest [27, 90•]. Epidemiological and clinical studies focused their attention on an increasingly important concept in both clinical care of older persons and research in aging, i.e., frailty, a biological syndrome of decreased ability 
Table 1 Principal studies on the association of different operational definitions of frailty or frailty instruments with late-life cognitive decline, mild cognitive impairment (MCI), dementia, Alzheimer's disease (AD), vascular dementia (VaD), and other different cognitive outcomes

\begin{tabular}{|c|c|c|}
\hline Reference & Study design and sample & Frailty and cognitive assessment \\
\hline Gill et al., 1996 [135] & $\begin{array}{l}\text { Population-based, longitudinal study; } \\
945 \text { respondents from the Project Safety } \\
\text { cohort, aged } 72 \text { years and older }\end{array}$ & $\begin{array}{l}\text { A composite measure of physical } \\
\text { performance, ADL, and MMSE }\end{array}$ \\
\hline $\begin{array}{l}\text { Strawbridge et al., } 1998 \\
\quad[136]\end{array}$ & $\begin{array}{l}\text { Population-based, longitudinal study; } \\
574 \text { Alameda County Study }\end{array}$ & $\begin{array}{l}1994 \text { Frailty Measure with four items } \\
\text { assessing cognitive functioning }\end{array}$ \\
\hline
\end{tabular}

respondents, aged 65-102 years
Fried et al., 2001 [19]

Rockwood et al., 2004 [24]

Ottenbacher et al., 2005 [134]

Rockwood et al., 2005 [25]

Rockwood et al., 2007 [114]

Buchmanet al., 2007
Population-based, longitudinal study; 5,745 older individuals from the CHS, aged 65 years and older

Population-based, longitudinal study; 9,008 older individuals from the CSHA aged 65 years and older

Population-based, longitudinal study (1 year); 621 Mexican American men and women aged 70 and older from the H-EPESE

Population-based, longitudinal study; 2,305 older individuals from the CSHA aged 65 years and older

Population-based, longitudinal study; 728 institutionalized older adults in the second clinical examination cohort of the CSHA aged 65 years and older

Population-based, longitudinal study (3 years); 823 older persons (mean age: 80.4 years) without dementia who participated in the Rush Memory and Aging Project
CHS frailty phenotype and MMSE

The operational and rules-based definition of frailty of the CSHA was based on the GSS, a scale combining aspects of cognitive and functional performance to describe various degrees of frailty; cognitive functions were also measured with the $3 \mathrm{MS}$

MMSE and physical frailty phenotype operalizionated slightly modifying the CHS criteria based on four frailty components and excluding physical activity

CSHA Clinical Frailty Scale and 3MS

CSHA Frailty Index, CSHA Clinical Frailty Scale, CHS phenotype, and 3MS

Physical frailty phenotype operalizionated slightly modifying the CHS criteria and based on four frailty components. Diagnoses of AD and DLB were made according to the NINCDS-ADRDA and the Report of the Consortium on DLB International Workshop. The MMSE was used to describe the cohort, while scores on other 19 neuropsychological tests were used to create a composite
Principal results

The risk of dependence increased with worsening performance on both objective measures of physical skills and standardized assessment of cognitive status. Impairments in physical performance and cognitive status were shown to contribute independently to the risk of functional dependence, even after controlling for potential confounders

Frail persons reported reduced activities, poorer cognitive function, and lower life satisfaction. Cumulative predictors over the previous three decades included heavy drinking, cigarette smoking, physical inactivity, depression, social isolation, fair or poor perceived health, prevalence of chronic symptoms, and prevalence of chronic conditions

Lower cognition was associated with the frailty physical phenotype (despite exclusion of those with MMSE $<18$ )

Among those participants described as mildly frail, $71.3 \%$ had functional impairment alone, $14.4 \%$ had cognitive impairment alone, and $14.3 \%$ had both. For those who were moderately or severely frail, coincident functional and cognitive impairments were more common, occurring in $28.1 \%$

The baseline MMSE total score was significantly predictive of frailty at 1 -year follow-up in men, but not in women

Participants with higher scores on the CSHA Clinical Frailty Scale were more likely to be cognitively than those with lower scores. This frailty instrument performed better than measures of cognition, function or comorbidity in assessing risk for death

All three frailty measures were significantly associated with an increased risk of mortality, disability and cognitive decline, measured with the modified 3MS. When pairs of frailty measures were included in the models, only the CSHA Frailty Index was associated with a higher risk of mortality and decline in the $3 \mathrm{MS}$

Both baseline level of frailty and annua rate of change in frailty were associated with an increased risk of incident AD. Furthermore, the level of frailty and rate of change in frailty were also associated with the rate of cognitive decline 
Table 1 (continued)

\begin{tabular}{|c|c|}
\hline Reference & Study design and sample \\
\hline $\begin{array}{l}\text { Buchman et al., } 2008 \\
\quad[145]\end{array}$ & $\begin{array}{l}\text { Population-based, longitudinal study; } \\
\text { brain autopsies from } 165 \text { deceased } \\
\text { participants from the Rush Memory } \\
\text { and Aging Project }\end{array}$ \\
\hline $\begin{array}{l}\text { Samper-Ternent et al., } \\
2008 \text { [138] }\end{array}$ & $\begin{array}{l}\text { Population-based, longitudinal study } \\
\text { (10 years); } 1,370 \\
\text { noninstitutionalized Mexican } \\
\text { American men and women aged } \\
65 \text { years and older from the H- } \\
\text { EPESE with a MMSE } \geq 21 \text { at } \\
\text { baseline }\end{array}$ \\
\hline $\begin{array}{l}\text { Sarkisian et al., } 2008 \\
\quad[140]\end{array}$ & $\begin{array}{l}\text { Population-based, longitudinal study; } \\
\text { 1,118 high-functioning subjects aged } \\
70-79 \text { years from the MacArthur } \\
\text { Study of Successful Aging }\end{array}$ \\
\hline
\end{tabular}

measure of global cognitive function. The CIM was used for diagnostic classification purposes only

Physical frailty phenotype operalizionated nonverbal memory dementia according to the DSM-IV,

Boyle et al., 2010 [139]

Sourial et al., 2010 [100] older individuals aged 65-85 years from the Three-City Study

Raji et al., 2010 [149]

ospital-based, longitudinal study; 262 patients aged 65 years and olde with a diagnosis of dementia

Avila-Funes et al., 2009 [23]

Three population-based, longitudinal studies;

839 individuals aged 75 years and older from the MUNS, 1,600 individuals aged 65 years and older from the CSHA, and 1,164 individuals aged 65 years and older from the SIPA Population-based, longitudinal study (10 years); 942 non-frail Mexican American men and women aged 65 years and older from the $\mathrm{H}$ EPESE
Physical frailty phenotype operalizionated slightly modifying the CHS criteria and based on four frailty components. Diagnoses of AD and DLB were made according to the NINCDS-ADRDA and the Report of the Consortium on DLB International Workshop criteria. Neuropathological measures of AD pathology, Lewy bodies, and cerebral infarcts were also obtained

Physical frailty phenotype operalizionated slightly modifying the CHS criteria based on four frailty components and excluding physical activity and MMSE slightly modifying the CHS criteria. Cognitive function was assessed using reliable tests of language, executive function, spatial ability, and verbal and

The CGA-based MPI and diagnosis of NINCDS-ADRDA, and NINDSAIREN criteria

Physical frailty phenotype operalizionated slightly modifying the CHS criteria, MMSE, and IST. Diagnosis of dementia according to the DSM-IV criteria

Physical frailty proximate to death was related to level of $\mathrm{AD}$ pathology on postmortem examination but was not related to the presence of cerebral infarcts or LBD. This association was similar in persons with and without dementia

A statistically significant association between frailty and subsequent decline in cognitive function over a 10 -year period was found in older Mexican Americans

Two subdimensions of frailty were identified, and cognitive impairment was part of a frailty subdimension, including slower gait, weaker grip, and lower physical activity, further increasing evidence that physical performance tests are sensitive indicators of cognitive impairment, and further supporting the hypothesis that cognitive impairment may be intrinsic to frailty

The MPI accurately stratified hospitalized elderly patients with dementia into groups at varying risk of short- and long-term all-cause mortality

Frail individuals with cognitive impairment have a higher risk of IADL and ADL disability and of incident hospitalization and dementia than subjects with none of these conditions, even after adjusting for potentially confounding variables

Physical frailty phenotype operalizionated slightly modifying the CHS criteria and based on four frailty components. Diagnoses of AD and MCI were made according to the NINCDS-ADRDA criteria and CSHA clinical criteria. The MMSE was used to describe the cohort, while scores on other 19 neuropsychological tests were used to create a composite measure of global cognitive function. The CIM was used for diagnostic classification purposes only

Seven domains of frailty were evaluated: nutrition, physical activity, mobility, strength, energy, cognition, and mood

MMSE and hysical frailty phenotype operalizionated slightly modifying the CHS criteria based on four frailty components and excluding physical activity
Higher level of physical frailty predicted the development of MCI and is associated with an accelerated rate of cognitive decline in older persons

In two of these population-based studies (CSHA and MUNS) presence of deficits for all domains separated from absence of deficits. In the SIPA, there was separation in all domains except cognition

Non-frail older Mexican Americans with low cognitive scores were significantly more likely to acquire one or more components of frailty 
Table 1 (continued)

\begin{tabular}{lll}
\hline Reference $\quad$ Study design and sample & Frailty and cognitive assessment
\end{tabular}

Armstrong et al., 2010

Aranda et al., 2011 [150]

Mitnitski et al., 2011

[116]

Mitnitski et al., 2011

[117]

Song et al., 2011 [118]

Auyeung et al., 2011

Avila-Funes et al., 2011

O’Halloran et al., 2011 [126]

Jacobs et al., 2011 [123]

Ní Mhaoláin et al., 2011 [125]

Solfrizzi et al., 2012 [127]

Jurschik et al., 2012 [128]

Doba et al., 2012 [121]
Database of 23,952 patients receiving community care in the home or in long-term care institutions across Ontario, Canada, with subjects aged $81.7 \pm 7.4$ years

Population-based, longitudinal study (2 years); 963 non-frail older subjects persons aged 75 years and older who participated in the $\mathrm{H}$ EPESE

Population-based, longitudinal study (5 years); 9,266 individuals of the CSHA sample subjects aged $75.8 \pm 7.1$ years

Population-based, longitudinal study (5 years); 2,305 individuals from the CSHA sample of subjects aged $83.1 \pm 6.9$ years

Population-based, longitudinal study (5 and 10 years); 5,909 individuals from the CSHA aged 65 years and older

Population-based, cross-sectional study; cognitively normal people aged 65 years and older and living in Hong Kong.

Population-based, cross-sectional study; 475 community-dwelling subjects aged 70 years and older from the Mexican Study of Nutritional and Psychosocial Markers of Frailty

Cross-sectional convenient sample of 384 community dwelling participants over 60 years from Ireland

Population-based, cross-sectional and longitudinal study (5 years); 840 individuals from the Jerusalem Longitudinal Cohort Study sample of subjects aged 85 years

Participants were recruited through the cross-sectional ECAD study from an Irish tertiary center; 115 patients were assessed, of which 95 with a diagnosis of $\mathrm{AD}$ and 20 with a diagnosis of MCI mean age was 74 years

Population-based, longitudinal study (3 and 7 years); 2,581 individuals from the ILSA sample of 5,632 subjects aged 65-84 years

Population-based, cross-sectional study; 628 individuals from community dwelling adults aged $75+$ in Spain; mean age: $81.3 \pm 5$ years

Population-based, longitudinal study (5 years); 407 individuals from the Japanese Health Research Volunteer Study sample of subjects aged $78 \pm 5$ years
CSHA Frailty Index, CHESS scale, and EFS and diagnosis of dementia (criteria not specified)

MMSE and physical frailty phenotype operalizionated slightly modifying the CHS criteria based on four frailty components and excluding physical activity

CSHA Frailty Index and five-year change in errors on $3 \mathrm{MS}$ grouped into categories of 3

CSHA Frailty Index, CSHA Clinical Frailty Scale, CHS frailty phenotype and fiveyear change in errors on 3MS grouped into categories of 3

Frailty Index of "non-traditional" risk factors for dementia and diagnosis of dementia according to the DSM-III-R and diagnosis of $\mathrm{AD}$ according to NINCDS-ADRDA criteria

BMI, grip strength, chair stand, step length, slowed walk, composite score on neuromuscular test and 4-year change in MMSE

Physical frailty phenotype operalizionated slightly modifying the CHS criteria, cognitive impairment was assessed with MMSE, and IST and considered as an additional frailty criterion

Physical frailty phenotype operalizionated with the CHS criteria and SART Task

Physical frailty phenotype operalizionated with the CHS criteria and MMSE

Physical frailty phenotype operalizionated slightly modifying the CHS criteria and probable AD diagnosed according to the NINCDS-ADRDA criteria and MCI according to international consensus criteria

Physical frailty phenotype operalizionated slightly modifying the CHS criteria and diagnosis of dementia according to the DSM-III-R, NINCDS-ADRDA, and ICD-10 criteria

Physical frailty phenotype operalizionated with the CHS criteria and Pfeiffer's Test for cognitive function. Cognitive impairment was $\geq 3$ errors

MDS cognitive performance scale. Selfreported cognitive change and 5-year change in CSHA Clinical Frailty Scale over 10 years than those with higher cognitive scores

Among participants, $40 \%$ classified in the frailest category had a diagnosis of dementia compared with $11 \%$ of those in the least frail category

Respondents at risk of increasing frailty had lower levels of cognitive functioning at baseline

Frailty at baseline associated with cognitive change in men and women

All measures of frailty at baseline associated with cognitive decline

Frailty at baseline was associated with the incidence of $\mathrm{AD}$ and dementia of all types over 5-year and 10-year intervals

Underweight, grip strength, and chair stand predicted cognitive decline in men, whereas only grip strength predicted lower MMSE at follow-up in women

Low physical activity and cognitive impairment appeared to be the more important contributors of functional disability

More errors and greater variability in performance speed in frail compared to non-frail participants

Frailty status was significantly associated with cognitive impairment. After adjustment, frailty alone was predictive of subsequent 5-year mortality

Frailty was a distinct entity measurable in $\mathrm{AD}$ and $\mathrm{MCI}$ that correlates with age and increasing comorbid illness rather than markers of cognitive decline and illness severity

Lower cognition was associated with physical frailty. Frail demented patients were at higher risk of allcause mortality over 3- and 7-year follow-up periods, but not of disability

Cognitive impairment was $20 \%$ in frail population compared to $5.3 \%$ in non-frail older subjects

Subjective cognitive changes at baseline were significantly associated with development of frailty at follow up. There was no significant association between 
Table 1 (continued)

\begin{tabular}{|c|c|c|}
\hline Reference & Study design and sample & Frailty and cognitive assessment \\
\hline Sourial et al., 2012 [101] & $\begin{array}{l}\text { Database from five different } \\
\text { population-based studies ( } 2 \text { EPESE } \\
\text { sites, LASA, MHAS, and NuAge); a } \\
\text { total of } 14,217 \text { individuals with } \\
\text { mean age ranged from } 72.4 \text { to } \\
75.6 \text { years }\end{array}$ & $\begin{array}{l}\text { Seven frailty domain measures (nutrition, } \\
\text { physical activity, mobility, strength, } \\
\text { energy, cognition, and mood) were } \\
\text { selected from each study and } \\
\text { dichotomized into presence or absence } \\
\text { of a frailty marker }\end{array}$ \\
\hline
\end{tabular}

75.6 years

Langlois et al., 2012

[131]

Macuco et al., 2012

Yassuda et al., 2012

Bilotta et al., 2012 [142]

Bilotta et al., 2012 [143]

Cano et al., 2012 [153•]

Avila-Funes et al., 2012

[147]

Solfrizzi et al., 2013

[146]

Shimada et al., 2013

[132]
Cross-sectional study; 83 community dwelling adults aged between 69 and 81 recruited through advertisement in newspapers and locally

Population-based, cross-sectional study; 487 individuals from the FIBRA study sample (Brazil) of subjects aged 65 years and over

Population-based, cross-sectional study; 487 individuals from the FIBRA study sample (Brazil) of subjects aged 65 years and over

Cross-sectional and longitudinal study (1 year); 109 participants attending an outpatient geriatric clinic in Italy aged 65 years and older (median age 84 years)

Cross-sectional and longitudinal study (1 year); 265 participants attending an outpatient geriatric clinic in Italy aged 65 years and older (mean age 81.5 years)

Population-based, longitudinal study (10 years); 1,815 Mexican American men and women aged 67 years and older from the $\mathrm{H}$ EPESE

Population-based, longitudinal study (7 years); 5,480 older individuals aged 65-85 years from the ThreeCity Study

Population-based, longitudinal study (3.5 years); 2,581 individuals from the ILSA sample of 5,632 subjects aged 65-84 years

Population-based, cross-sectional study ; 5,104 older individuals from the Obu Study of Health Promotion for the Elderly (OSHPE) sample of
Frail if present 2 of the following 3 criteria: physical frailty phenotype with the CHS criteria or CSHA Frailty Index or low score on MPP. MMSE and evaluation of the following cognitive domains: verbal abstract reasoning, episodic memory, working memory, speed of processing and executive function with the CHS criteria and MMSE

Physical frailty phenotype operalizionated with the CHS criteria, MMSE, and the $\mathrm{BCSB}$

Physical frailty phenotype operalizionated with the SOF criteria and diagnosis of $\mathrm{AD}$ according to the DSM-IV-Text Revised

Physical frailty phenotype operalizionated with the SOF criteria and diagnosis of dementia according to the DSM-IV-Text Revised

Physical frailty phenotype operalizionated slightly modifying the CHS criteria and MMSE > 21

Physical frailty phenotype operalizionated slightly modifying the CHS criteria, MMSE, and IST. Diagnosis of dementia according to the DSM-IV criteria and $\mathrm{VaD}$ according to the NINDS-AIREN criteria

Physical frailty phenotype operalizionated slightly modifying the CHS criteria and diagnosis of dementia according to the DSM-III-R, NINCDS-ADRDA, and ICD-10 criteria

Physical frailty phenotype operalizionated slightly modifying the CHS criteria and MCI diagnosed according to international consensus criteria
Physical frailty phenotype operalizionated
Principal results

MDS and development of frailty at follow-up

Among frailty markers consistently aggregated in the five samples, strength had the highest contribution overall in explaining differences among participants across the samples; mobility and energy followed as the next most discriminating markers; and nutrition and cognition appeared to be least discriminating

Presence of frailty affected executive function and processing speed. No effect on working memory, episodic memory, or abstract verbal reasoning

Frail older adults had significantly worse performance on the MMSE

Frail older adults performed lower than non-frail in most cognitive variables

Among AD patients, $50 \%$ were frail, 28 were pre-frail, and $22 \%$ were robust. Frail, demented patients were at higher risk of all-cause mortality over 1-year follow-up period

Dementia in $45 \%$ of frail participants compared with $32 \%$ in pre-frail and $33 \%$ robust, although differences were not statistically significant

As MMSE score declined over time, the percent of frail individuals increased in a linear fashion. Frailty and cognitive impairment are independent risk factors for mortality after controlling for all covariates. When both cognitive impairment and frailty were added to the model, hazard ratio for individuals with cognitive impairment was no longer statistically significant

Frailty was marginally associated with greater risk of all types of dementia and was not associated with incident $\mathrm{AD}$, but frailty status was independently associated with incident $\mathrm{VaD}$

Over a 3.5-year follow-up, frailty syndrome was associated with a significantly increased risk of overall dementia and, in particular, VaD, while the risk of $\mathrm{AD}$ or other types of dementia did not significantly change in frail individuals compared with subjects without frailty syndrome

The overall prevalence of frailty, MCI, and frailty and MCI combined was $11.3 \%, 18.8 \%$, and $2.7 \%$, respectively. A significant 
Table 1 (continued)

\begin{tabular}{|c|c|c|c|}
\hline Reference & Study design and sample & Frailty and cognitive assessment & Principal results \\
\hline & $\begin{array}{l}\text { subjects aged } 65 \text { years or older, } \\
\text { mean age } 71 \text { years }\end{array}$ & & $\begin{array}{l}\text { relationships between frailty and } \\
\mathrm{MCI} \text { also was found }\end{array}$ \\
\hline Gray et al., 2013 [148] & $\begin{array}{l}\text { Population-based, longitudinal study } \\
\text { (6.5 years); } 2,619 \text { individuals from } \\
\text { the Adult Changes in Thought } \\
\text { (ACT) study sample of subjects } \\
\text { aged } 65 \text { years and older }\end{array}$ & $\begin{array}{l}\text { Physical frailty phenotype operalizionated } \\
\text { with the CHS criteria and diagnosis of } \\
\text { dementia according to the DSM-IV, } \\
\text { diagnosis of possible and probable AD } \\
\text { according to NINCDS-ADRDA criteria. } \\
\text { Non-AD dementia consisted of all } \\
\text { dementias not classified as possible or } \\
\text { probable AD }\end{array}$ & $\begin{array}{l}\text { Frailty was associated with higher risk } \\
\text { of developing non-AD dementia but } \\
\text { not AD. Although frailty was not } \\
\text { associated with all-cause dementia } \\
\text { in the entire sample, an association } \\
\text { did exist in participants with higher } \\
\text { cognitive scores }\end{array}$ \\
\hline $\begin{array}{l}\text { Kulmala et al., } 2014 \\
\text { [144] }\end{array}$ & $\begin{array}{l}\text { Population-based, cross-sectional } \\
\text { study; } 654 \text { persons aged } 76- \\
100 \text { years (mean } 82 \pm 4.6 \text { years) } \\
\text { from the Geriatric Multidisciplinary } \\
\text { Strategy for the Good Care ofthe } \\
\text { Elderly (GeMS) study, Kuopio, } \\
\text { Finland }\end{array}$ & $\begin{array}{l}\text { Physical frailty phenotype operalizionated } \\
\text { with the CHS criteria, diagnosis of } \\
\text { dementia, AD, and VaD according to the } \\
\text { DSM-IV criteria and cognitive } \\
\text { impairment evaluated with MMSE }\end{array}$ & $\begin{array}{l}\text { Frail persons were almost } 8 \text { times more } \\
\text { likely to have cognitive impairment, } \\
8 \text { times more likely to have some } \\
\text { kind of dementia, almost } 6 \text { times } \\
\text { more likely to have } \mathrm{VaD} \text {, and over } 4 \\
\text { times more likely to have AD than } \\
\text { persons who were robust }\end{array}$ \\
\hline Han et al. 2014 [133] & $\begin{array}{l}\text { Population-based, cross-sectional } \\
\text { study; } 10,388 \text { nationally } \\
\text { representative sample aged } 65 \text { years } \\
\text { and older from the } 2008 \text { Living } \\
\text { Profiles of Older People Survey, } \\
\text { South Korea }\end{array}$ & $\begin{array}{l}\text { Physical frailty phenotype operalizionated } \\
\text { with the CHS criteria and cognitive } \\
\text { function was assessed using the Korean } \\
\text { version of the MMSE }\end{array}$ & $\begin{array}{l}\text { Frail subjects showed a higher } \\
\text { percentage of cognitive impairment, } \\
\text { with some gender differences } \\
\text { ( } 55.8 \% \text { in men, } 35.2 \% \text { in women). } \\
\text { Cognitive impairment was } \\
\text { associated with a higher likelihood } \\
\text { of frailty in community-dwelling } \\
\text { older men and women }\end{array}$ \\
\hline
\end{tabular}

ADL, activities of daily living; MMSE, Mini Mental State Examination; CSH, Cardiovascular Health Study; CSHA, Canadian Study of Health and Aging; GSS, Geriatric Status Scale; 3MS, modified Mini Mental State Examination; H-EPESE, Hispanic Established Population for the Epidemiological Study of the Elderly; NINCDS-ADRDA, National Institute of Neurological and Communicative Disorders and Stroke-Alzheimer's Disease and Related Disorders Association; DLB, dementia with Lewy bodies; CIM, Complex Ideational Material; CGA, Comprehensive Geriatric Assessment; MPI, Multidimensional Prognostic Index; DSM-IV, Diagnostic and Statistical Manual of Mental Disorders-IV; NINDS-AIREN, National Institute of Neurological Disorders and Stroke-Association Internationale pour la Recherche et l'Enseignement en Neurosciences; IST, Isaac Set Test; IADL, instrumental activities of daily living; MUNS, Montreal Unmet Needs Study; SIPA, French acronym of the System of Integrated Services for Older Persons study; CHESS, Changes in Health, End-Stage Disease and Signs and Symptoms; EFS, Edmonton Frail Scale; DSM-III-R, Diagnostic and Statistical Manual of Mental Disorders-III revised; BMI, body mass index; SART, Sustained Attention Response Time; ECAD, Enhancing Care in Alzheimer's Disease; ILSA, Italian Longitudinal Study on Aging; ICD-10, International Statistical Classification of Diseases and Related Health Problems, 10th revision; MDS, Minimum Data Set; LASA, Longitudinal Aging Study Amsterdam; MHAS, Mexican Health and Aging Study; NuAge, Nutrition as a determinant of successful aging; MPP, Modified Physical Performance; BCSB, Brief Cognitive Screening Battery; SOF, Study of Osteoporotic Fractures

to respond to stressors and an increased vulnerability to adverse outcomes [19]. However, frailty is, at present, a more elusive concept, and how best to operationalize this syndrome is still controversial [91]. Some definitions are based on physical diminution in the elderly person $[19,92,93]$. In particular, the "phenotypic" or physical definition of frailty or the "biological syndrome model" was proposed by Fried and colleagues working with the Cardiovascular Health Survey (CHS) [19]. By convention, the CHS definition of physical frailty proposes five items: unintentional weight loss, exhaustion, weakness, slow walking speed, and low levels of physical activity. An older individual is said to be frail when three or more are present, "pre-frail" when they exhibit only one or two of these characteristics, and "robust" when they have none [19]. Other definitions, criticizing this concept [94-97], suggested that an integral approach is needed for the concept of frailty, an approach in which the focus is not exclusively on physical problems in older people, but which also incorporates psychological and social problems, and is thus based on the integral functioning of the individual $[98,99]$. A recent integral conceptual working definition of frailty takes into account of the principles formulated earlier and combines essential components of existing conceptual definitions of frailty [98, 99]. This definition indicates frailty as a dynamic state affecting an individual who experiences losses in one or more domains of human functioning (physical, psychological, social), which is caused by the influence of a range of variables and which increases the risk of adverse outcomes [99]. Therefore, an emerging consensus promotes a definition of frailty on the basis of a multidimensional approach [99-102], so the evaluation of frailty employs a frailty index, which is calculated by considering a number of potential deficits. These deficits can be symptoms, signs, diseases, disabilities or abnormal laboratory values [102], so developing an integral conceptual definition of frailty as a multisystem physiological change occurring in the elderly that determine an increase of risk for accelerated physical and cognitive decline, disability and death even in absence of specific diseases [99-102]. 
Therefore, the second model that emerged in recent years is the frailty index based on accumulation of deficits or cumulative burden index proposed by Rockwood and collegues $[103,104]$, in which frailty is defined as an accumulation of health conditions and deficits.

\section{Cognitive Frailty: Multidimensional and Phenotypic} Approach

In physical or phenotypic frailty [19] or in frailty indexes with a multidimensional nature $[103,104]$, this clinical syndrome is generally associated with a greater risk for adverse healthrelated outcomes, such as falls, disability, hospitalization, permanent institutionalization, and death [105•]. However, in recent years, the prevention of frailty may be important in preventing cognitive-related adverse health outcomes, including delirium [26] and late-life cognitive disorders [27, 90•]. Therefore, physical frailty [106, 107], psychological frailty, and social frailty cannot be seen in isolation from each other, and, in particular, cognition has already been considered as a component of frailty [23]; indeed, this conceptualization of frailty is based on a holistic view of the person [99-101]. In fact, in recent years, frailty is acknowledged to be not only a biological or physiological state, but also a multidimensional concept $[20,102,108]$. The multidimensional nature of the concept of frailty demands a multidisciplinary approach.

A list of eight frailty risk factors that are mentioned to be of great importance to the concept of frailty were identified in a systematic review that evaluated clinimetric properties [102], including in the physical dimension: nutritional status, physical activity, mobility, strength, and energy, in the psychological dimension: cognition and mood, and in the social dimension: lack of social contacts and social support. On this basis, at least 20 frailty instruments have been described [102], and cognition was present in only $40 \%$ of them [27]. All these frailty instruments are multidimensional in nature, and mostly based on a standardized Comprehensive Geriatric Assessment (CGA) $[27,109,110]$. However, the overall results of the assessment by using these frailty instruments suggested that they are mainly developed and validated as risk assessment tools, and not as possible outcome measures [102]. Only a few studies made a comparison between frailty instruments, concluding that different instruments may identify older people at risk of adverse health outcome [111], but they may capture different subpopulations [112, 113]. In particular, in older individuals institutionalized in nursing homes, comparing the CHS physical definition of frailty [19], the Canadian Study of Health and Aging (CSHA) Clinical Frailty Scale [25], and the Frailty Index [111], whereas all these frailty measures were significantly associated with an increased risk of mortality, disability and cognitive decline, measured with the Mini Mental State Examination (MMSE) in its modified form (3MS), when pairs of frailty measures were included in the models, only the Frailty Index was associated with a higher risk of mortality and decline in the 3MS [114] (Table 1). Furthermore, a study examined the relationships among seven frailty domains (nutrition, physical activity, mobility, strength, energy, cognition, and mood), using data from three population-based studies. In two of these studies, presence of deficits for all domains separated from absence of deficits. In the third population-based study, there was separation in all domains except cognition. All these data may suggest that frailty is a multidimensional concept for which the relationships among domains differ according to the population characteristics. These domains, with the possible exception of cognition, appeared to aggregate together and share a common underlying construct [100]. Alternatively, it may be that frailty involves specific aspects of cognition not measured in the three studies, such as executive function or psychomotor speed [106, 107], rather than overall impairment. More recently, the same authors analyzed data from five populationbased studies of aging, and among frailty markers consistently aggregated in the five samples, strength had the highest contribution overall in explaining differences among participants across the samples; mobility and energy followed as the next most discriminating markers; and nutrition and cognition appeared to be least discriminating [101]. A Canadian study of 23,952 home care recipients found that $40 \%$ of participants classified in the frailest category using a frailty index based on an accumulation of deficits approach had a diagnosis of dementia compared to $11 \%$ of those in the least frail category [115] (Table 1). Other three Canadian studies, using the population-based sample of the CSHA of adults in the community and institutionalized care, proposed that different measures of frailty at baseline were associated in a 5-year followup with cognitive decline $[116,117]$ and dementia and $\mathrm{AD}$ over 5-year and 10-year intervals [118] (Table 1).

Only very few studies explored the multidimensional impairment as a frailty concept in hospitalized older patients. In particular, the Multidimensional Prognostic Index (MPI) was effective in predicting short- and longterm mortality risk in elderly subjects with dementia admitted to a geriatric hospital ward [119] (Table 1), and given that in patients with dementia, clinical outcome and mortality result from a combination of psychological, biological, functional, and environmental factors, tools that effectively identify patients with different life expectancy should be multidimensional in nature. More recently, a multicentre study on 1,306 hospitalized patients in France showed that that screening for frailty with four different indexes based on multidimensional impairment at the beginning of a hospital stay can strongly predict 1 -year institutionalization and mortality related to frailty, but not rapid cognitive decline (loss of $\geq 3$ points on MMSE) [120] (Table 1). Overall taken together these findings supported the 
concept that considering multidimensional aggregate information and frailty syndrome could be very important for predicting short- and long-term all-cause mortality in older subjects with dementia and that it may be important for the identification of the more adequate management of these patients. Finally, a Japanese populationbased study also showed a reciprocal relationship, suggesting that cognitive impairment may indicate the development of frailty measured with the CSHA Clinical Frailty Scale [121] (Table 1).

Moreover, the physical or phenotypic definition of frailty has been proposed in several studies linking frailty models and late-life cognitive decline or dementia $[27,90 \bullet, 122 \bullet \bullet]$. A series of cross-sectional [23, 123-133] and longitudinal studies [19, 23, 134-141] investigated the relationship between physical/biological frailty and MCI or late-life cognitive impairment/decline (Table 1). In the cross-sectional component of the Italian Longitudinal Study on Aging (ILSA), both lower cognition and greater depressive symptoms were associated with physical frailty [127]. Other findings from the Three-City Study suggested that cognitive impairment improved the predictive validity of the operational definition of physical frailty, increasing the risk to develop disability. On the contrary, risk of death also tended to be higher in cognitively impaired frail participants than in their non-frail counterparts without cognitive impairment, even if the results were not statistically significant [23]. In the Mexican Study of Nutritional and Psychosocial Markers of Frailty, in which physical frailty phenotype was operalizionated slightly modifying the CHS criteria and cognitive impairment was considered as an additional frailty criterion, low physical activity and cognitive impairment appeared to be the more important contributors of functional disability [124]. In the Jerusalem Longitudinal Cohort Study, prevalence of cognitive impairment (MMSE $\leq 24)$ in frail older subjects was $53.3 \%$, with frailty status significantly associated with cognitive impairment [123]. In a population-based study from South Korea, frail older subjects showed a higher percentage of cognitive impairment, with some gender differences $(55.8 \%$ in men, $35.2 \%$ in women) [133]. In different population-based studies from Spain and Brazil, the prevalence of cognitive impairment in physical frail older subjects ranged from $20 \%$ [128] to $39 \%[129,130]$, whereas in a sample of 5,104 older community dwellers in Japan, the combined prevalence of frailty and MCI was only $2.7 \%$, with a significant relationships between frailty and MCI [132]. Furthermore, in a sample from an Irish tertiary center, frailty was a distinct entity measurable in $\mathrm{AD}$ and MCI that correlates with age and increasing comorbid illness rather than markers of cognitive decline and illness severity [125]. Finally, some cognitive domains were found significantly associated with frailty in some cross-sectional studies on community dwelling older people, i.e., executive functions and processing speed [131], and poorer sustained attention [126]. In longitudinal studies, lower cognition was associated with the frailty physical phenotype in the CHS, despite exclusion of those subjects with MMSE $<18$ [19]. Several other studies have also reported that physical frailty was associated with low cognitive performance at baseline [134-136]. In particular, in the Hispanic Established Populations Epidemiologic Studies of the Elderly (H-EPESE), the baseline MMSE total score was significantly predictive of frailty at 1-year follow-up in men, but not in women [134]. After adjustment, in Three-City Study, frail persons with cognitive impairment were significantly more likely to develop disability over a 4-year period [23]. Two longitudinal population-based studies indicated frailty syndrome as a predictor of cognitive impairment in a 10-year follow-up [138], and of the rate of cognitive decline in a 3-year period [137]. The Rush Memory and Aging Project also found that physical frailty increased the risk for MCI [139], although there is still controversy as to whether cognitive impairment may be a symptom of frailty or whether MCI is a separate syndrome, or indeed, a sign of early dementia [139]. In a large population-based study conducted in Hong Kong, underweight, grip strength and chair stand predicted cognitive decline in men, while only grip strength predicted lower MMSE at follow-up in women [141]. Finally, a study provided preliminary empirical support for the existence of subdimensions of physical frailty within the CHS model [19]. In particular, two subdimensions were identified, and cognitive impairment was part of a frailty subdimension, including slower gait, weaker grip, and lower physical activity, further increasing evidence that physical performance tests are sensitive indicators of cognitive impairment, and further supporting the hypothesis that cognitive impairment may be intrinsic to frailty [140]. In fact, although some have referred to the CHS model of frailty as the "biological" model of frailty (in contrast to other models that include social and psychological criteria), these findings call this into question, because several variables in the CHS phenotype of frailty appear to be integrally related to cognitive impairment [140].

Also when the cognitive outcomes were dementia, $\mathrm{AD}$, or $\mathrm{VaD}$, a series of cross-sectional [142-144] and longitudinal studies [137, 145-148] investigated these associations with physical/biological frailty (Table 1). In particular, two small Italian studies investigated the prevalence of $\mathrm{AD}$ and dementia in patients with frailty identified with Study of Osteoporotic Fractures (SOF) criteria, which operationalized physical frailty with a simpler adaptation of the more complex CHS criteria $[142,143]$. In the first study of 109 AD patients attending an outpatient geriatric clinic, $50 \%$ were frail, $28 \%$ were pre-frail, and $22 \%$ were robust [142]. In the second study of 265 outpatients, dementia was identified in $45 \%$ of frail participants compared with $32 \%$ in pre-frail, and $33 \%$ robust, although differences were not statistically significant [143]. In a cross-sectional population-based study in Finland, frail 
persons were almost eight times more likely to have cognitive impairment, eight times more likely to have some kind of dementia, almost six times more likely to have $\mathrm{VaD}$, and more than four times more likely to have $\mathrm{AD}$ than persons who were robust [144]. Furthermore, different studies have reported that physical frailty may be associated with incidence of $\mathrm{AD}$ [137], $\mathrm{VaD}[146,147]$, non-AD dementias [148], and AD pathology in older persons with and without dementia [145] (Table 1). In the unadjusted model of the Three-City Study, being frail at baseline led to twice the cumulative risk of dementia at 4 years, although after adjusting for sociodemographic and health covariates frailty status did not remain a statistically significant predictor of dementia [23]. Findings from the Rush Memory and Aging Project raised the possibility that $\mathrm{AD}$ pathology may contribute to frailty or that frailty and $\mathrm{AD}$ pathology share a common pathogenesis [145]. In fact, physical frailty proximate to death was related to level of $\mathrm{AD}$ pathology on postmortem examination but was not related to the presence of cerebral infarcts or Lewy body disease. This association was similar in persons with and without dementia and was unchanged even after considering level of physical activity, various physical performance measures, and chronic diseases [145]. One longitudinal population-based study has examined the association of frailty or change in frailty with incident AD [137]. In fact, other findings from the Rush Memory and Aging Project on 820 subjects during a 3-year follow-up showed that the risk of developing $\mathrm{AD}$ was 2.5 times higher when physical frailty was present at baseline [137]. Some studies, however, have found associations with frailty and specific dementia subtypes [146-148]. During a 3.5-year follow-up, in the ILSA, frailty syndrome was associated with a significantly increased risk of overall dementia and, in particular, $\mathrm{VaD}$, whereas the risk of $\mathrm{AD}$ or other types of dementia did not significantly change in frail individuals compared with subjects without frailty syndrome [146]. A later analysis of the Three City Study confirmed the effect of frailty on incident $\mathrm{VaD}$ and overall dementia, but not on $\mathrm{AD}$ [147]. Data from the population-based Adult Changes in Thought (ACT) study also suggested an association between frailty and incident non-AD dementia (all dementias not classified as possible or probable AD), but not with AD [148]. Finally, some studies showed a reciprocal relationship indicating that cognitive impairment also may indicate the development of frailty $[149,150]$ (Table 1). In fact, a low MMSE score was independently associated with increased risk of physical frailty over a 10-year period in older Mexican Americans [149] and over a 2-year period in the same sample in adults older than age 75 years [150], suggesting that cognitive status may be an early marker for future risk of physical frailty (Table 1).

On the basis of this growing and extensive body of epidemiological evidence, an international consensus group comprised of investigators from the International Academy of
Nutrition and Aging (IANA) and the International Association of Gerontology and Geriatrics (IAGG) recently convened in Toulouse, France, to establish a definition for "cognitive frailty" in older adults $[125,151]$. "Cognitive frailty" is a heterogeneous clinical manifestation characterized by the simultaneous presence of both physical frailty and cognitive impairment [125]. In particular, the proposed criteria defining this novel age-related condition included presence of physical frailty and cognitive impairment, operationalized with the CHS phenotypic/biological model of frailty and with a Clinical Dementia rating Scale (CDR) of 0.5 (questionable dementia, a stage of the dementia continuum similar to $\mathrm{MCI}$ ), and exclusion of concurrent $\mathrm{AD}$ dementia or other dementias [125]. The IANA/IAGG consensus group proposed a series of screening and diagnostic tools exploring and identifying multiple domains/causes of frailty, including cognitive and psychological status, in order to design effective interventions for cognitive frailty [125], a field that needs further development. In 2006, our group used the term "cognitive frailty" in the title of a review article on predementia syndrome and vascular risk factors, suggesting a particular state of cognitive vulnerability in MCI and other similar clinical entities exposed to vascular risk with a subsequent increased progression to overt dementia [152]. Therefore, cognitive frailty should be validated as a possible determinant of the principal healthrelated outcomes of the different frailty models, i.e., disability, hospitalizations, and mortality. Some longitudinal populationbased studies investigated cognitive frailty models linked to increased disability and all-cause mortality [23, 127, 142, 153•] (Table 1). In the ILSA, frail, demented patients were at higher risk of all-cause mortality over 3-and 7-year follow-up periods, but not of disability [127]. Other two recent studies investigated the survival of patients with frailty and cognitive impairment. Findings from the Three-City Study suggested that cognitive impairment improved the predictive validity of the operational definition of physical frailty, increasing the risk to develop disability. On the contrary, risk of death also tended to be higher in cognitively impaired frail participants than in their non-frail counterparts without cognitive impairment, even if the results were not statistically significant [23]. In a small Italian study of 109 AD patients attending an outpatient geriatric clinic, 1 year after enrolment, frailty was an independent predictor of death after correction for age, sex, dependence in the basic activities of daily living (ADL), severity of cognitive impairment, and comorbidity [142]. Finally, more recently, in the H-EPESE, the cognitive frailty construct was operalizionated with the CHS frailty phenotype plus MMSE $<21$ and followed as a possible determinant of all-cause mortality in a 10-year follow-up [153•]. As MMSE score declined over time, the percent of frail individuals increased and frailty and cognitive impairment were independent risk factors for mortality after controlling for all covariates. However, when both cognitive impairment and frailty 
("cognitive frailty") were added to the model, hazard ratio for individuals with cognitive impairment was no longer statistically significant [153•], suggesting that frailty may be a stronger predictor of mortality than cognitive impairment at least in this population of older Mexican Americans.

\section{Nutrition and Frailty}

Current epidemiological evidence supported the hypothesis that modifiable vascular, lifestyle-related, and metabolic factors also may be associated with the development of frailty syndrome and frailty components in later life [154-156], opening new potential routes for the prevention of these disability-related conditions. In particular, among potentially modifiable risk factors, the impact of several nutritional factors on frailty and its components has been the subject of recent interest [22-, 154, 157, 158]. A more sedentary lifestyle, a reduction in metabolic cell mass and, consequently, lower energy expenditure and dietary intake are important contributors to the progression of frailty. A decline in intake is in turn associated with the risk of developing a suboptimal nutritional state or multiple micronutrient deficiencies [159]. In fact, undernutrition may be a major cause of frailty $[160,161]$, and older persons with protein energy undernutrition, a treatable condition, have poorer cognitive performance $[162 \cdot, 163]$.

The transition from independence to disability in older adults is characterized by detectable changes in body composition and physical function. Epidemiologic studies have shown that weight loss, reduced caloric intake, and the reduced intake of specific nutrients are associated with such changes [155]. The mechanisms underlying these associations remain unclear, and different hypotheses have been suggested, including the reduction of the antioxidant effects of some nutrients. Among macronutrients, low protein intake was associated with higher prevalence of frailty among InCHIANTI study participants older than 65 years of age [157]. Consumption of specific micronutrients also has been associated with frailty-related outcomes. In the InCHIANTI study, higher dietary intake of vitamin C was significantly correlated with measures of knee extension and lower extremity performance [164], whereas the same study also reported an association between low intake of vitamin $\mathrm{D}, \mathrm{E}$, and $\mathrm{C}$ with prevalence of frailty [157]. Nutrient biomarkers have been extensively studied in association with physical function and frailtyrelated outcomes. An association between low circulating levels of vitamin $\mathrm{E}$ and the presence of frailty in the InCHIANTI sample also was found [158]. In the Women's Health and Aging Study (WHAS), at baseline, frail women had significantly lower serum concentrations of vitamins D, E, and B6 and carotenoids compared with their non-frail peers $[165,166]$. Moreover, non-frail women in the lowest quartiles of serum $\alpha$ tocopherol, 25-hydroxyvitamin-D [25(OH)D], and carotenoids had an increased risk of becoming frail during the follow-up [165]. Furthemore, women in the lowest quartile of serum concentrations of vitamin B6, B12, and selenium had significantly higher risk of developing disability in ADL during a 3-year follow-up compared with women in the upper quartiles [167]. Finally, observational and clinical trials testing the relationship between vitamin $\mathrm{D}$ and physical performance provided mixed results $[168,169]$. These suggestions also proposed to examine dietary patterns rather than single nutrients. In community-dwelling older adults, after a 6-year follow-up, higher adherence to a Mediterraneanstyle diet was associated with lower odds of developing frailty compared with those with lower adherence [170•]. A higher adherence to a Mediterranean-style diet at baseline was associated with a lower risk of low physical activity and low walking speed but not with feelings of exhaustion and poor muscle strength [170•]. Moreover, more recently, higher adherence to MeDi score was cross-sectionally associated with lower risk of being frail [171]. A cohort study conducted in French elderly community dwellers showed an inverse association between adherence to a Mediterranean-style diet and risk of disability in women, whereas no association was evidenced in men [172]. Among frailty components, high adherence to a Mediterranean-style diet was associated with a slower decline of mobility over 8 years of follow-up in community dwelling older persons [173], and walking speed over 8 years was faster among those with higher MeDi adherence at baseline [174], suggesting a long-term effect of this diet on mobility performance in older age.

Nutrition and physical exercise may be important and modifiable factors potentially affecting the frailty status of the older person $[21 \bullet, 22 \bullet$. Some systematic reviews of home-based and group-based exercise interventions for frail older people showed that exercise have the potential to improve outcomes of mobility and functional ability [175, 176]. Furthermore, nutritional interventions might be able to address the impaired nutrition and weight loss of frailty. In fact, prefrailty and frailty were associated with lower nutritional status and higher food insufficiency in the participants older than age 60 years of the Third National Health and Nutrition Examination Survey (NHANES III) [177, 178]. Frailty also was associated with increased risk of malnutrition in men and women older than age 75 years [179]. An observational study of nutritional intervention with 
400 kcal liquid meal, frail individuals showed lower hunger recuperation compared to non-frail individuals, $4 \mathrm{~h}$ after supplementation [180]. A recent meta-analysis of 12 studies on more than 1,800 older persons suggested that complete caloric nutritional supplements not only produced weight gain but also improved cognition [181•]. In frail nursing home residents, a nutrient- and energy-dense oral nutritional supplement not only improved nutritional status but also tended to improve quality of life [182]. On the other hand, one RCT that investigated the effects of exercise and nutritional supplementation in 100 frail elderly people in long-term care reported that such supplementation had no effect on muscle strength, gait speed, stair climbing, or physical activity [183]. However, more recently, one RCT among frail individuals aged 65 years and older with low socioeconomic status, showed that after 12 weeks of protein-energy supplementation, usual gait speed decreased by $1.0 \%$ in the intervention compared with the control group, while there was no difference in handgrip strength between the two groups [184]. The role of both nutrition and exercise was examined in only one pilot RCT conducted among Chinese men and women aged 65-79 years. The intervention groups received either nutritional consultation or problem-solving therapy (psychotherapy model) and the control groups had neither nutritional consultation nor problem-solving therapy. Primary outcome was improvement of the CHS phenotype of frailty by at least one category (from pre-frail to robust, or from frail to pre-frail or robust). The group that received nutritional consultation showed significantly higher improvement of the frailty phenotype compared to the control group after 3 months of intervention, but not at 6 and 12 months [185••].

\section{Conclusions}

Given the very limited therapeutic value of drugs currently used in the treatment of cognitive impairment and dementia, it results evident the necessity to potentially individualize new strategies able to prevent and to slow down the progression of MCI and dementia. Higher adherence to a Mediterranean-type diet was associated with cognitive decline although the MeDi combines several foods and nutrients already separately proposed as potential protective factors against dementia syndromes and late-life cognitive decline. Therefore, maintaining a healthy diet may have an impact on many possible risk factors for cognitive decline, and the models to follow seem to be the MeDi and DASH diets among healthy diets. On the basis of this evidence, the evaluation of the MeDi or DASH diets on cognitive outcomes seems of particular interest and recent prospective studies focusing on $\mathrm{AD}$ and dementia appeared to be really promising. Among different dietary patterns, higher adherence to the MeDi was associated with a reduced risk of cognitive impairment, $\mathrm{MCI}$, and $\mathrm{AD}$, as well as the transition from $\mathrm{MCI}$ to $\mathrm{AD}$, and decreased all-causes mortality in $\mathrm{AD}$ patients. These findings suggested that adherence to the MeDi may affect not only the risk for $\mathrm{AD}$, but also for MCI, probably influencing the evolution of cognitive performances over time and subsequent disease progression. However, while for the vascular hypothesis there was clear evidence about a protective role of DASH diet, and particularly MeDi and its nutrients in preventing all cardiovascular conditions linked to dementia, for the other possible mechanisms it was only possible to suggest hypothetical biological pathways taken into account the results from animal studies. Therefore, the lack of reproducibility in some results on the linked between healthier diet and cognitive decline and the speculative aspect of the biological pathways presented, suggested us to be cautious.

Other modifiable, age-related conditions linked to late-life cognitive decline may be important for the prevention of these devastating disorders. Among these conditions, frailty in older adults is a syndrome corresponding to a vulnerability to stressors and it tends to be considered as a major risk for adverse outcomes in older age. A recent and growing body of epidemiological evidence suggested that frailty may increase the risk of future cognitive decline and that cognitive impairment may increase the risk of frailty suggesting that cognition and frailty may interact in advancing aging. The etiology of frailty is multifactorial and besides hormonal and inflammatory processes, nutritional influences may be of major relevance. Nutritional interventions might be able to address the impaired nutrition and weight loss of frailty. There have been a limited number of RCTs investigating the role of nutrition on late-life cognitive disorders and frailty. There are difficulties in the design and conduction of RCTs in older persons, especially targeting complex conditions as frailty or $\mathrm{AD}$ and dementia. For example, if a change of dietary habits may play a major part on the prevention of frailty and late-life cognitive disorders, what is the role of genetic risk factors, or if these associations may be valid in populations with different dietary patterns? Other questions may address the underlying mechanisms and which is the most relevant component, among dietary micro- and macronutrients and their possible interactions. Answers to these questions will help us to better define the target populations for future preventive and therapeutic strategies also in older age. However, 
the reviewed epidemiological evidence clearly indicate the need to design and develop RCTs possibly addressing possible interactions in different populations with genetic factors and other possible confounders, and whether change in dietary patterns may protect against cognitive decline and $\mathrm{AD}$, also through the nutritional prevention of frailty.

Acknowledgments This research was supported by Programmi di Ricerca Scientifica di Rilevante Interesse Nazionale (PRIN) 2009 Grant 2009E4RM4Z.

\section{Compliance with Ethics Guidelines}

Conflict of Interest Francesco Panza, Vincenzo Solfrizzi, Rosanna Tortelli, Francesco Resta, Carlo Sabbà, and Giancarlo Logroscino declare that they have no conflict of interest.

Human and Animal Rights and Informed Consent This article does not contain any studies with human or animal subjects performed by any of the authors.

\section{References}

Papers of particular interest, published recently, have been highlighted as:

- Of importance

•. Of major importance

1. Brookmeyer R, Johnson E, Ziegler-Graham K, Arrighi HM. Forecasting the global burden of Alzheimer's disease. Alzheimers Dement. 2007;3:186-91.

2. Solfrizzi V, Capurso C, D'Introno A, Colacicco AM, Santamato A, Ranieri M, et al. Lifestyle-related factors in predementia and dementia syndromes. Expert Rev Neurother. 2009;8:133-58.

3. Peters R. The prevention of dementia. Int $\mathbf{J}$ Geriatr Psychiatry. 2009;24:452-8

4. de la Torre JC. Alzheimer's disease is incurable but preventable. J Alzheimers Dis. 2010;20:861-70.

5. Solfrizzi V, Panza F, Frisardi V, Seripa D, Logroscino G, Imbimbo BP, et al. Diet and Alzheimer's disease risk factors or prevention: the current evidence. Expert Rev Neurother. 2011;11:677-708.

6. Panza F, Solfrizzi V, Logroscino G, Maggi S, Santamato A, Seripa $\mathrm{D}$, et al. Current epidemiological approaches to the metaboliccognitive syndrome. J Alzheimers Dis. 2012;30 Suppl 2:S31-75.

7. Richard E. Moll van Charante EP, van Gool WA. Vascular risk factors as treatment target to prevent cognitive decline. J Alzheimers Dis. 2012;32:733-40.

8. McKhann GM, Knopman DS, Chertkow H, Hyman BT, Jack Jr CR, Kawas CH, et al. The diagnosis of dementia due to Alzheimer's disease: recommendations from the National Institute on Aging-Alzheimer's Association workgroups on diagnostic guidelines for Alzheimer's disease. Alzheimers Dement. 2011;7:263-9.

9. Albert MS, DeKosky ST, Dickson D, Dubois B, Feldman HH, Fox NC, et al. The diagnosis of mild cognitive impairment due to Alzheimer's disease: recommendations from the National Institute on Aging-Alzheimer's Association workgroups on diagnostic guidelines for Alzheimer's disease. Alzheimers Dement. 2011;7: 270-9.

10. Sperling RA, Aisen PS, Beckett LA, Bennett DA, Craft S, Fagan AM, et al. Toward defining the preclinical stages of Alzheimer's disease: recommendations from the National Institute on AgingAlzheimer's Association workgroups on diagnostic guidelines for Alzheimer's disease. Alzheimers Dement. 2011;7:280-92.

11. Bateman RJ, Xiong C, Benzinger TL, Fagan AM, Goate A, Fox $\mathrm{NC}$, et al. Dominantly Inherited Alzheimer Network. Clinical and biomarker changes in dominantly inherited Alzheimer's disease. N Engl J Med. 2012;367:795-804.

12. Villemagne VL, Burnham S, Bourgeat P, Brown B, Ellis KA, Salvado $\mathrm{O}$, et al. Amyloid $\beta$ deposition, neurodegeneration, and cognitive decline in sporadic Alzheimer's disease: a prospective cohort study. Lancet Neurol. 2013;12:357-67. This prospective cohort study, applying a multidisciplinary approach including $\beta$ amyloid $(A \beta)$ and structural imaging, constructed a model of the natural history of $A \beta$ deposition and the sequence of changes in brain structure and cognition leading to sporadic Alzheimer's disease (AD). According to their estimates, A $\beta$ deposition is a slow process that extends for more than two decades.

13. Panza F, Solfrizzi V, Imbimbo BP, Tortelli R, Santamato A, Logroscino G. Amyloid-based immunotherapy for Alzheimer's disease in the time of prevention trials: the way forward. Expert Rev Clin Immunol. 2014;10:405-19.

14. Panza F, Solfrizzi V, Frisardi V, Capurso C, D'Introno A, Colacicco $\mathrm{AM}$, et al. Disease-modifying approach to the treatment of Alzheimer's disease: from alpha-secretase activators to gammasecretase inhibitors and modulators. Drugs Aging. 2009;26:537-55.

15. Panza F, Logroscino G, Imbimbo BP, Solfrizzi V. Is there still any hope for amyloid-based immunotherapy for Alzheimer's disease? Curr Opin Psychiatry. 2014;27:128-37.

16. Grant WB. Dietary links to Alzheimer's disease: 1999 Update. J Alzheimers Dis. 1999;1:197-201.

17. Solfrizzi V, Panza F, Capurso A. The role of diet in cognitive decline. J Neural Transm. 2003;110:95-110.

18. Luchsinger JA, Mayeux R. Dietary factors and Alzheimer's disease. Lancet Neurol. 2004;3:579-87.

19. Fried LP, Tangen CM, Walston J, Newman AB, Hirsch C, Gottdiener J, et al. Cardiovascular Health Study Collaborative Research Group. Frailty in older adults: evidence for a phenotype. J Gerontol A Biol Sci Med Sci. 2001;56:M146-56.

20. Walston J, Hadley EC, Ferrucci L, Guralnik JM, Newman AB, Studenski SA, et al. Research agenda for frailty in older adults: toward a better understanding of physiology and etiology: summary from the American Geriatrics Society/National Institute on Aging Research Conference on Frailty in Older Adults. J Am Geriatr Soc. 2006;54:991-1001.

21. Clegg A, Young J, Iliffe S, Rikkert MO, Rockwood K. Frailty in elderly people. Lancet. 2013;381:752-62. A recent and comprehensive review on frailty in older people, addressing the epidemiology, pathophysiology, assessment of frailty, and the development of interventions potentially effective for this clinical syndrome.

22. Kelaiditi E, van Kan GA, Cesari M. Frailty: role of nutrition and exercise. Curr Opin Clin Nutr Metab Care. 2014;17:32-9. This is the most recent review on prevention of frailty in older people, comprehensively addressing the role of nutrition and exercise on frailty, supporting preventive strategies against disability in older person.

23. Avila-Funes JA, Amieva H, Barberger-Gateau P, Le Goff M, Raoux N, Ritchie K, et al. Cognitive impairment improves the predictive validity of the phenotype of frailty for adverse health outcomes: the Three-City Study. J Am Geriatr Soc. 2009;57:453-61.

24. Rockwood K, Howlett SE, MacKnight C, Beattie BL, Bergman $\mathrm{H}$, Hébert R, et al. Prevalence, attributes, and outcomes of fitness 
and frailty in community-dwelling older adults: Report from the Canadian Study of Health and Aging. J Gerontol A Biol Sci Med Sci. 2004;59A:1310-7.

25. Rockwood K, Song X, MacKnight C, Bergman H, Hogan DB, McDowell I, et al. A global clinical measure of fitness and frailty in elderly people. Can Med Assoc J. 2005;173:489-95.

26. Eeles EM, White SV, O'Mahony SM, Bayer AJ, Hubbard RE. The impact of frailty and delirium on mortality in older inpatients. Age Ageing. 2012;41:412-6.

27. Panza F, Solfrizzi V, Frisardi V, Maggi S, Sancarlo D, Addante F, et al. Different models of frailty in predementia and dementia syndromes. J Nutr Health Aging. 2011;15:711-9.

28. Harrison FE. A critical review of vitamin $\mathrm{C}$ for the prevention of age-related cognitive decline and Alzheimer's disease. J Alzheimers Dis. 2012;29:711-26.

29. Viña J, Lloret A, Giraldo E, Badia MC, Alonso MD. Antioxidant pathways in Alzheimer's disease: possibilities of intervention. Curr Pharm Des. 2011;17:3861-4.

30. Luchsinger JA, Tang MX, Miller J, Green R, Mayeux R. Relation of higher folate intake to lower risk of Alzheimer disease in the elderly. Arch Neurol. 2007;64:86-92.

31. Darvesh AS, Carroll RT, Bishayee A, Geldenhuys WJ, Van der Schyf CJ. Oxidative stress and Alzheimer's disease: dietary polyphenols as potential therapeutic agents. Expert Rev Neurother. 2010;10:729-45.

32. Hu N, Yu JT, Tan L, Wang YL, Sun L, Tan L. Nutrition and the risk of Alzheimer's disease. Biomed Res Int. 2013;2013:524820.

33. Shah R. The role of nutrition and diet in Alzheimer's disease: a systematic review. J Am Med Dir Assoc. 2013;14:398-402.

34. Galasko DR, Peskind E, Clark CM, Quinn JF, Ringman JM, Jicha GA, et al. Antioxidants for Alzheimer disease: a randomized clinical trial with cerebrospinal fluid biomarker measures. Arch Neurol. 2012;69:836-41.

35. Wald DS, Kasturiratne A, Simmonds M. Effect of folic acid, with or without other B vitamins, on cognitive decline: meta-analysis of randomized trials. Am J Med. 2010;123:522-7.

36. Presse N, Belleville S, Gaudreau P, Greenwood CE, Kergoat MJ, Morais JA, et al. Vitamin $\mathrm{K}$ status and cognitive function in healthy older adults. Neurobiol Aging. 2013;34:2777-83.

37. Coley N, Andrieu S, Gardette V, Gillette-Guyonnet S, Sanz C, Vellas B, et al. Dementia prevention: methodological explanations for inconsistent results. Epidemiol Rev. 2008;30:35-66.

38. Frisardi V, Panza F, Seripa D, Imbimbo BP, Vendemiale G, Pilotto A, et al. Nutraceutical properties of Mediterranean diet and cognitive decline: possible underlying mechanisms. J Alzheimers Dis. 2010;22:715-40.

39. Solfrizzi V, Frisardi V, Capurso C, D'Introno A, Colacicco AM, Vendemiale G, et al. Dietary fatty acids in dementia and predementia syndromes: epidemiological evidence and possible underlying mechanisms. Ageing Res Rev. 2010;9:184-99.

40. Cunnane SC, Plourde M, Pifferi F, Bégin M, Féart C, BarbergerGateau P. Fish, docosahexaenoic acid and Alzheimer's disease. Prog Lipid Res. 2009;48:239-56.

41. Solfrizzi V, Colacicco AM, D'Introno A, Capurso C, Torres F, Rizzo C, et al. Dietary intake of unsaturated fatty acids and agerelated cognitive decline: a 8.5-year follow-up of the Italian Longitudinal Study on Aging. Neurobiol Aging. 2006;27:1694 704.

42. Naqvi AZ, Harty B, Mukamal KJ, Stoddard AM, Vitolins M, Dunn JE. Monounsaturated, trans, and saturated Fatty acids and cognitive decline in women. J Am Geriatr Soc. 2011;59:837-43.

43. Fotuhi M, Mohassel P, Yaffe K. Fish consumption, long-chain omega-3 fatty acids and risk of cognitive decline or Alzheimer disease: a complex association. Nat Clin Pract Neurol. 2009;5: $140-52$.
44. van de Rest O, Geleijnse JM, Kok FJ, van Staveren WA, Hoefnagels WH, Beekman AT, et al. Effect of fish-oil supplementation on mental well-being in older subjects: a randomized, double-blind, placebo-controlled trial. Am J Clin Nutr. 2008;88: 706-13.

45. van de Rest O, Geleijnse JM, Kok FJ, van Staveren WA, Dullemeijer C, Olderikkert MG, et al. Effect of fish oil on cognitive performance in older subjects: a randomized, controlled trial. Neurology. 2008;71:430-8.

46. Quinn JF, Raman R, Thomas RG, Yurko-Mauro K, Nelson EB, Van Dyck C, et al. Docosahexaenoic acid supplementation and cognitive decline in Alzheimer disease: a randomized trial. JAMA. 2010;304:1903-11.

47.• Martínez-Lapiscina EH, Clavero P, Toledo E, San Julián B, Sanchez-Tainta A, Corella D, et al. Virgin olive oil supplementation and long-term cognition: the PREDIMED-NAVARRA randomized, trial. J Nutr Health Aging. 2013;17:544-52. This key paper suggested that Mediterranean diet supplemented with extra virgin olive oil (1 l/week) for 6.5 years improved cognitive performance, while a supplement of mixed nuts $(30 \mathrm{~g} /$ day) had no effect. Persons taking extra virgin olive oil were less likely to develop mild cognitive impairment.

48. Friedland RP. Fish consumption and the risk of Alzheimer disease: is it time to make dietary recommendations? Arch Neurol. 2003;60:923-4.

49. Crichton GE, Bryan J, Murphy KJ, Buckley J. Review of dairy consumption and cognitive performance in adults: findings and methodological issues. Dement Geriatr Cogn Disord. 2010;30: 352-61. Comprehensive and unique review on the possible association between dairy intake and cognitive functioning.

50. Yamada M, Kasagi F, Sasaki H, Masunari N, Mimori Y, Suzuki G. Association between dementia and midlife risk factors: the radiation effects research foundation adult health study. J Am Geriatr Soc. 2003;51:410-4.

51. Kliem KE, Givens DI. Dairy products in the food chain: their impact on health. Annu Rev Food Sci Technol. 2011;2:21-36.

52. Kerola T, Kettunen R, Nieminen T. The complex interplay of cardiovascular system and cognition: how to predict dementia in the elderly? Int J Cardiol. 2011;150:123-9.

53. Henderson ST. High carbohydrate diets and Alzheimer's disease. Med Hypotheses. 2004;62:689-700.

54. Seneff S, Wainwright G, Mascitelli L. Nutrition and Alzheimer's disease: the detrimental role of a high carbohydrate diet. Eur J Intern Med. 2011;22:134-40.

55. Luchsinger JA, Tang MX, Mayeux R. Glycemic load and risk of Alzheimer's disease. J Nutr Health Aging. 2007;11:238-41.

56. Loef $\mathrm{M}$, Walach $\mathrm{H}$. Fruit, vegetables and prevention of cognitive decline or dementia: a systematic review of cohort studies. J Nutr Health Aging. 2012;16:626-30.

57. Barranco Quintana JL, Allam MF, Serrano Del Castillo A, Fernandez-Crehuet NR. Alzheimer's disease and coffee: a quantitative review. Neurol Res. 2007;29:91-5.

58. Santos C, Costa J, Santos J, Vaz-Carneiro A, Lunet N. Caffeine intake and dementia: systematic review and meta-analysis. J Alzheimers Dis. 2010;20 Suppl 1:S187-204.

59. Arab L, Khan F, Lam H. Epidemiologic evidence of a relationship between tea, coffee, or caffeine consumption and cognitive decline. Adv Nutr. 2013;4:115-22. A recent and in depth review of tea, coffee, and caffeine consumption and cognition.

60. Panza F, Frisardi V, Seripa D, Logroscino G, Santamato A, Imbimbo BP, et al. Alcohol consumption in mild cognitive impairment and dementia: harmful or neuroprotective? Int J Geriatr Psychiatry. 2012;27:1218-38.

61. Peters R, Peters J, Warner J, Beckett N, Bulpitt C. Alcohol, dementia and cognitive decline in the elderly. a systematic review. Age Ageing. 2008;37:505-12. 
62. Anstey KJ, Mack HA, Cherbuin N. Alcohol consumption as a risk factor for dementia and cognitive decline: meta-analysis of prospective studies. Am J Geriatr Psychiatry. 2009;17:542-55.

63. Neafsey EJ, Collins MA. Moderate alcohol consumption and cognitive risk. Neuropsychiatr Dis Treat. 2011;7:465-84.

64. Luchsinger JA, Noble JM, Scarmeas N. Diet and Alzheimer's disease. Curr Neurol Neurosci Rep. 2007;7:366-72.

65. Samieri C, Jutand MA, Féart C, Capuron L, Letenneur L, Barberger-Gateau P. Dietary patterns derived by hybrid clustering method in older people: association with cognition, mood, and self-rated health. J Am Diet Assoc. 2008;108:1461-71.

66. Sofi F, Macchi C, Abbate R, Gensini GF, Casini A. Effectiveness of the Mediterranean diet: can it help delay or prevent Alzheimer's disease? J Alzheimers Dis. 2010;20:795-801.

67. Eskelinen MH, Ngandu T, Tuomilehto J, Soininen H, Kivipelto M. Midlife healthy-diet index and late-life dementia and Alzheimer's disease. Dement Geriatr Cogn Dis Extra. 2011;1: 103-12.

68. Lourida I, Soni M, Thompson-Coon J, Purandare N, Lang IA, Ukoumunne OC, et al. Mediterranean diet, cognitive function, and dementia: a systematic review. Epidemiology. 2013;24:479-89. A comprehensive and systematic review synthesizing the available evidence on the association between adherence to Mediterranean diet and cognitive function or dementia.

69. Kesse-Guyot E, Andreeva VA, Jeandel C, Ferry M, Hercberg S, Galan P. A healthy dietary pattern at midlife is associated with subsequent cognitive performance. J Nutr. 2012;142:909-15.

70. Allès B, Samieri C, Féart C, Jutand MA, Laurin D, BarbergerGateau P. Dietary patterns: a novel approach to examine the link between nutrition and cognitive function in older individuals. Nutr Res Rev. 2012;25:207-22.

71. Ozawa M, Ninomiya T, Ohara T, Doi Y, Uchida K, Shirota $\mathrm{T}$, et al. Dietary patterns and risk of dementia in an elderly Japanese population: the Hisayama Study. Am J Clin Nutr. 2013;97:1076-82. A Japanese population-based study suggesting that a higher adherence to a Japanese-style diet with a dietary pattern characterized by a high intake of soybeans and soybean products, vegetables, algae, and milk and dairy products and a low intake of rice may be associated with reduced risk of dementia.

72. Tangney CC. DASH and Mediterranean-type dietary patterns to maintain cognitive health. Curr Nutr Rep. 2014;3:51-61. Complete and very updated review on the principal dietary patterns linked to the protection against dementia and late-life cognitive decline.

73. Solfrizzi V, Panza F. Mediterranean diet and cognitive decline. A lesson from the whole-diet approach: what challenges lie ahead? J Alzheimers Dis. 2014;39:283-6.

74. Hu FB. Dietary pattern analysis: a new direction in nutritional epidemiology. Curr Opin Lipidol. 2002;13:3-9.

75. Hooijmans CR, Rutters F, Dederen PJ, et al. Changes in cerebral blood volume and amyloid pathology in aged Alzheimer APP/PS1 mice on a docosahexaenoic acid (DHA) diet or cholesterol enriched Typical Western Diet (TWD). Neurobiol Dis. 2007;28: 16-29.

76. Studzinski CM, Li F, Bruce-Keller AJ, et al. Effects of short-term Western diet on cerebral oxidative stress and diabetes related factors in APP x PS1 knock-in mice. J Neurochem. 2009;108: $860-6$.

77. Gustaw-Rothenberg K. Dietary patterns associated with Alzheimer's disease: population based study. Int J Environ Res Public Health. 2009;6:1335-40.

78. Gu Y, Nieves JW, Stern Y, Luchsinger JA, Scarmeas N. Food combination and Alzheimer disease risk: a protective diet. Arch Neurol. 2010;67:699-706.
79. Akbaraly TN, Singh-Manoux A, Marmot MG, Brunner EJ. Education attenuates the association between dietary patterns and cognition. Dement Geriatr Cogn Disord. 2009;27:147-54.

80. Appel LJ, Brands MW, Daniels SR, Karanja N, Elmer PJ, Sacks FM, et al. Dietary approaches to prevent and treat hypertension: a scientific statement from the American Heart Association. Hypertension. 2006;47:296-308.

81. Sacks FM, Campos H. Dietary therapy in hypertension. N Engl J Med. 2010;362:2102-12.

82.• Smith PJ, Blumenthal JA, Babyak MA, Craighead L, WelshBohmer KA, Browndyke JN, et al. Effects of the dietary approaches to stop hypertension diet, exercise, and caloric restriction on neurocognition in overweight adults with high blood pressure. Hypertension. 2010;55:1331-8. A trial designed to improve cardiovascular outcomes in a high-risk U.S. population sample in which repeated cognitive testing has occurred over a short 4month period. Cognitive improvements were noted in both Dietary Approaches to Stop Hypertension (DASH) active treatments; a DASH dietary modification or a DASH dietary modification plus weight loss against usual care.

83. Norton MC, Dew J, Smith H, Fauth E, Piercy KW, Breitner JC, et al. Lifestyle behavior pattern is associated with different levels of risk for incident dementia and Alzheimer's disease: the Cache County study. J Am Geriatr Soc. 2012;60:405-12.

84.• Wengreen H, Munger RG, Cutler A, Quach A, Bowles A, Corcoran C, et al. Prospective study of dietary approaches to stop hypertension-and Mediterranean-style dietary patterns and agerelated cognitive change: the cache county study on memory, health and aging. Am J Clin Nutr. 2013;98:1272-81. Dietary Approaches to Stop Hypertension and Mediterranean diet scores were assessed in relation to repeated cognitive measures. Higher scores of each pattern were consistently associated higher cognitive function over an 11-year period in a U.S. cohort of 3,861 men and women.

85. Feart C, Samieri C, Barberger-Gateau P. Mediterranean diet and cognitive function in older adults. Curr Opin Clin Nutr Metab Care. 2010;13:14-8.

86. Psaltopoulou T, Sergentanis TN, Panagiotakos DB, Sergentanis IN, Kosti R, Scarmeas N. Mediterranean diet and stroke, cognitive impairment, depression: a meta-analysis. Ann Neurol. 2013;74: 580-91.

87. Singh B, Parsaik AK, Mielke MM, Erwin PJ, Knopman DS, Petersen RC, et al. Association of Mediterranean diet with mild cognitive impairment and Alzheimer's disease: a systematic review and meta-analysis. J Alzheimers Dis. 2014;39:271-82.

88. McMillan L, Owen L, Kras M, Scholey A. Behavioural effects of a 10-day Mediterranean diet. Results from a pilot study evaluating mood and cognitive performance. Appetite. 2011;56:143-7.

89.• Martínez-Lapiscina EH, Clavero P, Toledo E, Estruch R, SalasSalvadó J, San Julián B, et al. Mediterranean diet improves cognition: the PREDIMED-NAVARRA randomised trial. J Neurol Neurosurg Psychiatry. 2013;84:1318-25. This key paper was the first long-term prevention randomized trial that compared two interventions with Mediterranean diet (MeDi) versus a low-fat diet. An intervention with $\mathrm{MeDi}$ with supplementation with either extra-virgin olive oil or nuts appeared to improve cognition compared with a low-fat diet in a 6.5-year follow-up.

90. Robertson DA, Savva GM, Kenny RA. Frailty and cognitive impairment-A review of the evidence and causal mechanisms. Ageing Res Rev. 2013;12:840-51. A very comprehensive review on the relationship between frailty and cognitive impairment, also focusing on the possible mechanisms behind this association.

91. Rockwood K. Frailty and its definition: a worthy challenge. J Am Geriatr Soc. 2005;53:1069-70.

92. Buchner DM, Wagner EH. Preventing frail health. Clin Geriatr Med. 1992;8:1-17. 
93. Hamerman D. Toward an understanding of frailty. Ann Intern Med. 1999;130:945-50.

94. Rockwood K, Hogan DB, MacKnight C. Conceptualisation and measurement of frailty in elderly people. Drugs Aging. 2000;17: 295-302.

95. Markle-Reid M, Browne G. Conceptualizations of frailty in relation to older adults. J Adv Nurs. 2003;44:58-68.

96. Hogan DB, MacKnight C, Bergman H. Models, definitions, and criteria of frailty. Aging Clin Exp Res. 2003;15:1-29.

97. Levers MJ, Estabrooks CA, Ross Kerr JC. Factors contributing to frailty: literature review. J Adv Nurs. 2006;56:282-91.

98. Schuurmans H, Steverink N, Lindenberg S, Frieswijk N, Slaets JP. Old or frail: what tells us more? J Gerontol A Biol Sci Med Sci. 2004;59:M962-5.

99. Gobbens RJ, Luijkx KG, Wijnen-Sponselee MT, Schols JM. In search of an integral conceptual definition of frailty: opinions of experts. J Am Med Dir Assoc. 2010;11:338-43.

100. Sourial N, Wolfson C, Bergman H, Zhu B, Karunananthan S, Quail J, et al. A correspondence analysis revealed frailty deficits aggregate and are multidimensional. J Clin Epidemiol. 2010;63: $647-54$

101. Sourial N, Bergman H, Karunananthan S, Wolfson C, Guralnik J, Payette $\mathrm{H}$, et al. Contribution of frailty markers in explaining differences among individuals in five samples of older persons. J Gerontol A Biol Sci Med Sci. 2012;67:1197-204.

102. de Vries NM, Staal JB, van Ravensberg CD, Hobbelen JS, Olde Rikkert MG, Nijhuis-van der Sanden MW. Outcome instruments to measure frailty: a systematic review. Ageing Res Rev. 2011;10: 104-14.

103. Rockwood K, Fox RA, Stolee P, Robertson D, Beattie BL. Frailty in elderly people: an evolving concept. Can Med Assoc J. 1994;150:489-95.

104. Rockwood K, Mitnitski A. Frailty in relation to the accumulation of deficits. J Gerontol A Biol Sci Med Sci. 2007;62:722-7.

105. Rodríguez-Mañas L, Féart C, Mann G, Viña J, Chatterji S, Chodzko-Zajko W, et al. Searching for an operational definition of frailty: a Delphi method based consensus statement: the frailty operative definition-consensus conference project. J Gerontol A Biol Sci Med Sci. 2013;68:62-7. A modified Delphi process was used to attempt to achieve a consensus on the operational definition of frailty.

106. Studenski S, Hayes RP, Leibowitz RQ, Bode R, Lavery L, Walston $\mathrm{J}$, et al. Clinical Global Impression of Change in Physical Frailty: development of a measure based on clinical judgment. J Am Geriatr Soc. 2004;52:1560-6.

107. Bergman H, Ferrucci L, Guralnik J, Hogan DB, Hummel S, Karunananthan S, et al. Frailty: an emerging research and clinical paradigm issues and controversies. J Gerontol A Biol Sci Med Sci. 2007;62:731-7.

108. Fulop T, Larbi A, Witkowski JM, McElhaney J, Loeb M, Mitnitski A, et al. Aging, frailty and age-related diseases. Biogerontology. 2010;11:547-663.

109. Jones DM, Song X, Rockwood K. Operationalizing a frailty index from a standardized comprehensive geriatric assessment. J Am Geriatr Soc. 2004;52:1929-33.

110. Jones D, Song X, Mitnitski A, Rockwood K. Evaluation of a frailty index based on a comprehensive geriatric assessment in a population based study of elderly Canadians. Aging Clin Exp Res. 2005; 17:465-71.

111. Rockwood K, Andrew M, Mitnitski A. A comparison of two approaches to measuring frailty in elderly people. J Gerontol A Biol Sci Med Sci. 2007;62:738-43.

112. Cigolle CT, Ofstedal MB, Tian Z, Blaum CS. Comparing models of frailty: the health and retirement study. J Am Geriatr Soc. $2009 ; 57: 830-9$.
113. Pilotto A, Rengo F, Marchionni N, Sancarlo D, Fontana A, Panza $\mathrm{F}$, et al. Comparing the prognostic accuracy for all-cause mortality of frailty instruments: a multicentre 1-year follow-up in hospitalized older patients. PLoS One. 2012;7:e29090.

114. Rockwood K, Abeysundera MJ, Mitnitski A. How should we grade frailty in nursing home patients? J Am Med Dir Assoc. 2007;8:595-603.

115. Armstrong JJ, Stolee P, Hirdes JP, Poss JW. Examining three frailty conceptualizations in their ability to predict negative outcomes for home-care clients. Age Ageing. 2010;39:755-8.

116. Mitnitski A, Fallah N, Rockwood K. A multistate model of cognitive dynamics in relation to frailty in older adults. Ann Epidemiol. 2011;21:507-16.

117. Mitnitski A, Fallah N, Rockwood MR, Rockwood K. Transitions in cognitive status in relation to frailty in older adults: a comparison of three frailty measures. J Nutr Health Aging. 2011;15:863-7.

118. Song X, Mitnitski A, Rockwood K. Nontraditional risk factors combine to predict Alzheimer disease and dementia. Neurology. 2011;77:227-34.

119. Pilotto A, Sancarlo D, Panza F, Paris F, D'Onofrio G, Cascavilla L, et al. The Multidimensional Prognostic Index (MPI) based on a comprehensive geriatric assessment predicts short- and long-term mortality in hospitalized older patients with dementia. J Alzheimers Dis. 2009;18:191-9.

120. Dramé M, Novella JL, Jolly D, Lanièce I, Somme D, Heitz D, et al. Rapid cognitive decline, one-year institutional admission and one-year mortality: analysis of the ability to predict and inter-tool agreement of four validated clinical frailty indexes in the SAFEs cohort. J Nutr Health Aging. 2011;15:699-705.

121. Doba N, Tokuda Y, Goldstein NE, Kushiro T, Hinohara S. A pilot trial to predict frailty syndrome: the Japanese Health Research Volunteer Study. Exp Gerontol. 2012;47:638-43.

122.• Kelaiditi E, Cesari M, Canevelli M, van Kan GA, Ousset PJ, Gillette-Guyonnet S, et al. Cognitive frailty: rational and definition from an (I.A.N.A./I.A.G.G.) international consensus group. J Nutr Health Aging. 2013;17:726-34. An international consensus group comprised of investigators from the International Academy of Nutrition and Aging (IANA) and the International Association of Gerontology and Geriatrics (IAGG) proposed a definition for "cognitive frailty" in older adults.

123. Jacobs JM, Cohen A, Ein-Mor E, Maaravi Y, Stessman J. Frailty, cognitive impairment and mortality among the oldest old. J Nutr Health Aging. 2011;15:678-82.

124. Ávila-Funes JA, Pina-Escudero SD, Aguilar-Navarro S, Gutierrez-Robledo LM, Ruiz-Arregui L, Amieva H. Cognitive impairment and low physical activity are the components of frailty more strongly associated with disability. J Nutr Health Aging. 2011;15:683-9.

125. Ní Mhaoláin AM, Gallagher D, Crosby L, Ryan D, Lacey L, Coen $\mathrm{R}$, et al. Correlates of frailty in Alzheimer's disease and mild cognitive impairment. Age Ageing. 2011;40:630-3.

126. O'Halloran AM, Fan CW, Kenny RA, Pénard N, Galli A, Robertson IH. Variability in sustained attention and risk of frailty. J Am Geriatr Soc. 2011;59:2390-2.

127. Solfrizzi V, Scafato E, Frisardi V, Sancarlo D, Seripa D, Logroscino G, et al. Frailty syndrome and all-cause mortality in demented patients: the Italian Longitudinal Study on Aging. Age (Dordr). 2012;34:507-17.

128. Jürschik P, Nunin C, Botigué T, Escobar MA, Lavedán A, Viladrosa M. Prevalence of frailty and factors associated with frailty in the elderly population of Lleida, Spain: the FRALLE survey. Arch Gerontol Geriatr. 2012;55:625-31.

129. Macuco CR, Batistoni SS, Lopes A, Cachioni M, da Silva Falcão DV, Neri AL, et al. Mini-Mental State Examination performance 
in frail, pre-frail, and non-frail community dwelling older adults in Ermelino Matarazzo, São Paulo, Brazil. Int Psychogeriatr. 2012;24:1725-31.

130. Yassuda MS, Lopes A, Cachioni M, Falcao DV, Batistoni SS, Guimaraes VV, et al. Frailty criteria and cognitive performance are related: data from the FIBRA study in Ermelino Matarazzo, São Paulo, Brazil. J Nutr Health Aging. 2012;16: $55-61$.

131. Langlois F, Vu TT, Kergoat MJ, Chassé K, Dupuis G, Bherer L. The multiple dimensions of frailty: physical capacity, cognition, and quality of life. Int Psychogeriatr. 2012;24:1429-36.

132. Shimada H, Makizako H, Doi T, Yoshida D, Tsutsumimoto K, Anan Y, et al. Combined prevalence of frailty and mild cognitive impairment in a population of elderly Japanese people. J Am Med Dir Assoc. 2013;14:518-24

133. Han ES, Lee Y, Kim J. Association of cognitive impairment with frailty in community-dwelling older adults. Int Psychogeriatr. 2014;26:155-63.

134. Ottenbacher KJ, Ostir GV, Peek MK, Snih SA, Raji MA, Markides KS. Frailty in older Mexican Americans. J Am Geriatr Soc. 2005;53:1524-31.

135. Gill TM, Williams CS, Richardson ED, Tinetti ME. Impairments in physical performance and cognitive status as predisposing factors for functional dependence among nondisabled older persons. J Gerontol A Biol Sci Med Sci. 1996;51A:M283-8.

136. Strawbridge WJ, Shema SJ, Balfour JL, Higby HR, Kaplan GA. Antecedents of frailty over three decades in an older cohort. J Gerontol B Psychol Sci Soc Sci. 1998;53B:S9-16.

137. Buchman AS, Boyle PA, Wilson RS, Tang Y, Bennett DA. Frailty is associated with incident Alzheimer's disease and cognitive decline in the elderly. Psychosom Med. 2007;69: 483-9.

138. Samper-Ternent R, Al Snih S, Raji MA, Markides KS, Ottenbacher KJ. Relationship between frailty and cognitive decline in older Mexican Americans. J Am Geriatr Soc. 2008;56: 1845-52.

139. Boyle PA, Buchman AS, Wilson RS, Leurgans SE, Bennett DA. Physical frailty is associated with incident mild cognitive impairment in community-based older persons. J Am Geriatr Soc. 2010;58:248-55.

140. Sarkisian CA, Gruenewald TL, John Boscardin W, Seeman TE. Preliminary evidence for subdimensions of geriatric frailty: the MacArthur study of successful aging. J Am Geriatr Soc. 2008;56: 2292-7.

141. Auyeung TW, Lee JS, Kwok T, Woo J. Physical frailty predicts future cognitive decline - a four-year prospective study in 2737 cognitively normal older adults. J Nutr Health Aging. 2011;15: 690-4.

142. Bilotta C, Bergamaschini L, Nicolini P, Casè A, Pina G, Rossi SV, et al. Frailty syndrome diagnosed according to the Study of Osteoporotic Fractures criteria and mortality in older outpatients suffering from Alzheimer's disease: a one-year prospective cohort study. Aging Ment Health. 2012;16:273-80.

143. Bilotta C, Nicolini P, Casè A, Pina G, Rossi S, Vergani C. Frailty syndrome diagnosed according to the Study of Osteoporotic Fractures (SOF) criteria and adverse health outcomes among community-dwelling older outpatients in Italy. A one-year prospective cohort study. Arch Gerontol Geriatr. 2012;54:e23-8.

144. Kulmala J, Nykänen I, Mänty M, Hartikainen S. Association between Frailty and Dementia: a population-based study. Gerontology. 2014;60:16-21.

145. Buchman AS, Schneider JA, Leurgans S, Bennett DA. Physical frailty in older persons is associated with Alzheimer disease pathology. Neurology. 2008;71:499-504.
146. Solfrizzi V, Scafato E, Frisardi V, Seripa D, Logroscino G, Maggi $\mathrm{S}$, et al. Frailty syndrome and the risk of vascular dementia: the Italian Longitudinal Study on Aging. Alzheimers Dement. 2013;9: 113-22.

147. Avila-Funes JA, Carcaillon L, Helmer C, Carrière I, Ritchie K, Rouaud $\mathrm{O}$, et al. Is frailty a prodromal stage of vascular dementia? Results from the Three-City Study. J Am Geriatr Soc. 2012;60: 1708-12.

148. Gray SL, Anderson ML, Hubbard RA, LaCroix A, Crane PK, McCormick W, et al. Frailty and incident dementia. J Gerontol A Biol Sci Med Sci. 2013;68:1083-90.

149. Raji MA, Al Snih S, Ostir GV, Markides KS, Ottenbacher KJ. Cognitive status and future risk of frailty in older Mexican Americans. J Gerontol A Biol Sci Med Sci. 2010;65:1228-34.

150. Aranda MP, Ray LA, Snih SA, Ottenbacher KJ, Markides KS. The protective effect of neighborhood composition on increasing frailty among older Mexican Americans: a barrio advantage? J Aging Health. 2011;23:1189-217.

151. Woods AJ, Cohen RA, Pahor M. Cognitive frailty: frontiers and challenges. J Nutr Health Aging. 2013;17:741-3.

152. Panza F, D'Introno A, Colacicco AM, Capurso C, Parigi $\mathrm{AD}$, Capurso SA, et al. Cognitive frailty: predementia syndrome and vascular risk factors. Neurobiol Aging. 2006;27: 933-40.

153. Cano C, Samper-Ternent R, Al Snih S, Markides K, Ottenbacher KJ. Frailty and cognitive impairment as predictors of mortality in older Mexican Americans. J Nutr Health Aging. 2012;16:142-7. A population-based study with a 10-year follow-up investigating a cognitive frailty model linked to increased all-cause mortality in older adults.

154. Milaneschi Y, Tanaka T, Ferrucci L. Nutritional determinants of mobility. Curr Opin Clin Nutr Metab Care. 2010;13:625-9.

155. Inzitari M, Doets E, Bartali B, Benetou V, Di Bari M, Di Visser M. International Association Of Gerontology And Geriatrics (IAGG) Task Force For Nutrition In The Elderly. Nutrition in the agerelated disablement process. J Nutr Health Aging. 2011;15:599 604.

156. Lee JS, Auyeung TW, Leung J, Kwok T, Leung PC, Woo J. Physical frailty in older adults is associated with metabolic and atherosclerotic risk factors and cognitive impairment independent of muscle mass. J Nutr Health Aging. 2011;15:857-62.

157. Bartali B, Frongillo EA, Bandinelli S, Lauretani F, Semba RD, Fried LP, et al. Low nutrient intake is an essential component of frailty in older persons. J Gerontol A Biol Sci Med Sci. 2006;61: 589-93.

158. Ble A, Cherubini A, Volpato S, Bartali B, Walston JD, Windham $\mathrm{BG}$, et al. Lower plasma vitamin $\mathrm{E}$ levels are associated with the frailty syndrome: the InCHIANTI study. J Gerontol A Biol Sci Med Sci. 2006;61:278-83.

159. de Jong N, Chin A, Paw MJ, de Groot LC, de Graaf C, Kok FJ, et al. Functional biochemical and nutrient indices in frail elderly people are partly affected by dietary supplements but not by exercise. J Nutr. 1999;129:2028-36.

160. Morley JE. Developing novel therapeutic approaches to frailty. Curr Pharm Des. 2009;15:3384-95.

161. Cesari M. Perspective: protein supplementation against sarcopenia and frailty - future perspectives from novel data. J Am Med Dir Assoc. 2013;14:62-3.

162. Tamura BK, Bell CL, Masaki KH, Amella EJ. Factors associated with weight loss, low BMI, and malnutrition among nursing home patients: A systematic review of the literature. J Am Med Dir Assoc. 2013;14:649-55. A systematic review on factors associated with weight loss and poor nutrition in long term care to target high-risk institutionalized patients.

163. Morley JE. Cognition and nutrition. Curr Opin Clin Nutr Metab Care. 2014;17:1-4. 
164. Cesari M, Pahor M, Bartali B, Cherubini A, Penninx BW, Williams GR, et al. Antioxidants and physical performance in elderly persons: the Invecchiare in Chianti (InCHIANTI) study. Am J Clin Nutr. 2004;79:289-94.

165. Semba RD, Bartali B, Zhou J, Blaum C, Ko CW, Fried LP. Low serum micronutrient concentrations predict frailty among older women living in the community. J Gerontol A Biol Sci Med Sci. 2006;61:594-9.

166. Michelon E, Blaum C, Semba RD, Xue QL, Ricks MO, Fried LP. Vitamin and carotenoid status in older women: associations with the frailty syndrome. J Gerontol A Biol Sci Med Sci. 2006;61: 600-7.

167. Bartali B, Semba RD, Frongillo EA, Varadhan R, Ricks MO, Blaum CS, et al. Low micronutrient levels as a predictor of incident disability in older women. Arch Intern Med. 2006;166: 2335-40.

168. Annweiler C, Schott AM, Berrut G, Fantino B, Beauchet O. Vitamin D-related changes in physical performance: a systematic review. J Nutr Health Aging. 2009;13:893-8.

169. Bischoff-Ferrari HA, Dawson-Hughes B, Staehelin HB, Orav JE, Stuck AE, Theiler R, et al. Fall prevention with supplemental and active forms of vitamin D: a meta-analysis of randomised controlled trials. BMJ. 2009;339:b3692.

170. Talegawkar SA, Bandinelli S, Bandeen-Roche K, Chen P, Milaneschi Y, Tanaka T, et al. A higher adherence to a mediterranean-style diet is inversely associated with the development of frailty in community-dwelling elderly men and women. $\mathbf{J}$ Nutr. 2012;142:2161-6. A population-based study with a 6-year follow-up showing that higher adherence to a Mediterraneanstyle diet at baseline was associated with a lower risk for frailty. Among frailty components, a higher adherence to a Mediterranean-style diet at baseline was associated with lower odds of low physical activity as well as low walking speed.

171. Bollwein J, Diekmann R, Kaiser MJ, et al. Dietary quality is related to frailty in community-dwelling older adults. J Gerontol A Biol Sci Med Sci. 2013;68:483-9.

172. Féart C, Pérès K, Samieri C, Letenneur L, Dartigues JF, BarbergerGateau P. Adherence to a Mediterranean diet and onset of disability in older persons. Eur J Epidemiol. 2011;26:747-56.

173. Milaneschi Y, Bandinelli S, Corsi AM, Lauretani F, Paolisso G, Dominguez LJ, et al. Mediterranean diet and mobility decline in older persons. Exp Gerontol. 2011;46:303-8.

174. Shahar DR, Houston DK, Hue TF, Lee JS, Sahyoun NR, Tylavsky FA, et al. Adherence to mediterranean diet and decline in walking speed over 8 years in community-dwelling older adults. J Am Geriatr Soc. 2012;60:1881-8.

175. de Vries NM, van Ravensberg CD, Hobbelen JS, Olde Rikkert MG, Staal JB, Nijhuis-van der Sanden MW. Effects of physical exercise therapy on mobility, physical functioning, physical activity and quality of life in community-dwelling older adults with impaired mobility, physical disability and/or multi-morbidity: a meta-analysis. Ageing Res Rev. 2012;11:136-49.

176. Clegg A, Barber S, Young J, Forster A, Iliffe S. Do home-based exercise interventions improve outcomes for frail older people? Findings from a systematic review. Rev Clin Gerontol. 2012;22: 68-78.

177. Smit E, Crespo CJ, Michael Y, Ramirez-Marrero FA, Brodowicz GR, Bartlett S, et al. The effect of vitamin D and frailty on mortality among noninstitutionalized US older adults. Eur J Clin Nutr. 2012;66:1024-8.

178. Smit E, Winters-Stone KM, Loprinzi PD, Tang AM, Crespo CJ. Lower nutritional status and higher food insufficiency in frail older US adults. Br J Nutr. 2013;110:172-8.

179. Bollwein J, Volkert D, Diekmann R, Kaiser MJ, Uter W, Vidal K, et al. Nutritional status according to the mini nutritional assessment (MNA1) and frailty in community dwelling older persons: a close relationship. J Nutr Health Aging. 2013;17:351-6.

180. Serra-Prat M, Mans E, Palomera E, Clave P. Gastrointestinal peptides, gastrointestinal motility, and anorexia of aging in frail elderly persons. Neurogastroenterol Motil. 2013;25:291-345.

181. Allen VJ, Methven L, Gosney MA. Use of nutritional complete supplements in older adults with dementia: systematic review and meta-analysis of clinical outcomes. Clin Nutr. 2013;32:950-7. A meta-analysis showing that oral nutritional supplements may increase weight and improve cognition in persons with dementia.

182. Stange I, Bartram M, Liao Y, Poeschl K, Kolpatzik S, Uter W, et al. Effects of a low-volume, nutrient- and energy-dense oral nutritional supplement on nutritional and functional status: a randomized, controlled trial in nursing home residents. J Am Med Dir Assoc. 2013;14:628.e1-8.

183. Fiatarone MA, O’Neill EF, Ryan ND, Clements KM, Solares GR, Nelson ME, et al. Exercise training and nutritional supplementation for physical frailty in very elderly people. N Engl J Med. 1994;330:1769-75.

184. Kim C-O, Lee K-R. Preventive effect of protein-energy supplementation on the functional decline of frail older adults with low socioeconomic status: a community-based randomized controlled study. J Gerontol A Biol Sci Med Sci. 2013;68:309-16.

185.• Chan DC, Tsou HH, Yang RS, Tsauo JY, Chen CY, Hsiung CA, et al. A pilot randomized controlled trial to improve geriatric frailty. BMC Geriatr. 2012;12:58. One of the first pilot randomized controlled trials examining the effects of both nutritional consultation and exercise in frail older adults, although both interventions on frailty status were only short-term effective (3 months). 